\section{Zur Verbesserung der Klärung in Dekantierzentrifugen*}

\section{Werner Stahl und Thomas Langeloh**}

Zur Auslegung von Dekantierzentrifugen steht von der theoretischen Seite bisher nur das auf das Fliehkraftfeld übertragene Stokessche Gesetz und die daraus abgeleitete Theorie der äquivalenten Klärfläche zur Verfügung. Diese von Smith und Hebb [1] eingeführte Beziehung berücksichtigt nur pauschal die Klärfläche des Dekanters. Andere Auslegungsdaten, wie z. B. die Geometrie der Schnecke oder die Einstellung der Teichtiefe, werden dabei nicht berücksichtigt. Für den Durchsatz gilt nach der Theorie der äquivalenten Klärfläche folgende Beziehung:

$Q=\frac{4 \pi^{3}}{9} \frac{\Delta \varrho}{\eta} \gamma_{\mathrm{G}}^{2} n_{\mathrm{H}}^{2} L_{\mathrm{e}} r_{\mathrm{m}}^{2}$.

Eine Beschreibung der Abscheidung ist mit diesem Gesetz nicht im.mer möglich. Die Theorie der äquivalenten Klärfläche läßt sich

sh durch Korrekturfaktoren nicht immer an die Vorgänge in der Zentrifuge anpassen [2].

Bildet man mit Hilfe dieser Theorie ein Wachstumsgesetz, so erhält man für eine bestimmte zu trennende Suspension bei gleicher Zentrifugalbeschleunigung beider Maschinen - ähnliche Vergrößerung der Rotoren vorausgesetzt - eine Durchsatzsteigerung mit der zweiten Potenz des Vergrößerungsfaktors $i$ :

$Q_{\text {Haupt }}=i^{2} Q_{\text {Pilot }}$.

Diese Beziehung steht im Widerspruch zu vielen Ergebnissen der Praxis, wonach bei gleicher Beschleunigungsziffer eine Kapazitätserhöhung mit der dritten Potenz des Vergrößerungsfaktors beobachtet wurde.

Betrachtet man den Verlauf des Durchschlages - d.h. des Feststoffgehalts im Zentrat - als Funktion des Durchsatzes, so erkennt man, daß der Durchschlag bis zu einem gewissen, sehr gut reproduzierbaren Durchsatz $Q_{\text {krit }}$ zunächst nur schwach und danach sprunghaft ansteigt (Abb. 1). Dieser plötzliche, steile Anstieg läßt sich mit Hilfe der Theorie der äquivalenten Klärfläche nicht erklären;

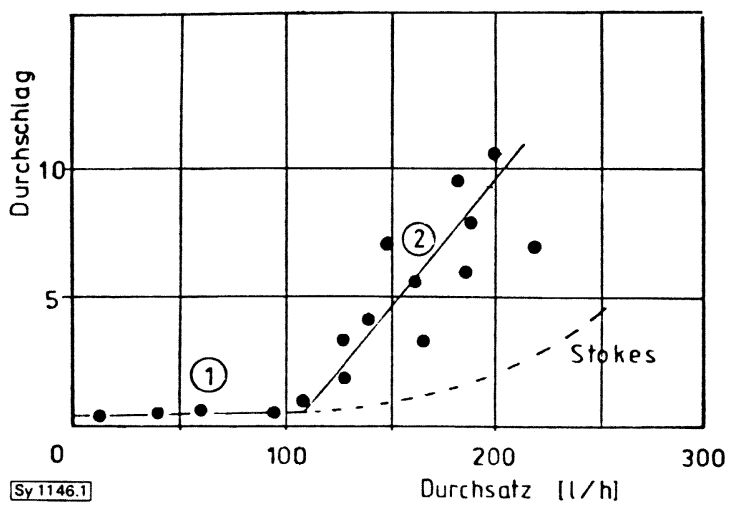

Abb. 1. Verlauf des Durchschlages als Funktion des Durchsatzes.

* Vortrag auf dem Jahrestreffen der Verfahrens-Ingenieure, 29. Sept. bis 1. Okt. 1982 in Basel.

** Prof. Dr.-Ing. W. Stahl (Vortragender) und Dipl.-Ing. Th. Langeloh, Institut für Mechanische Verfahrenstechnik und Mechanik der Univ. Karlsruhe (TH), Kaiserstr. 12, 7500 Karlsruhe. man würde einen wesentlich flacheren Kurvenverlauf erhalten. Es ist also anzunehmen, daß ab dem kritischen Durchsatz für die Beschreibung der Abscheidung ein anderes Gesetz gültig ist. Folgender Effekt ist dafür verantwortlich: Die mit zunehmendem Durchsatz steigende Schubspannung in der Flüssigkeit auf der Oberfläche der Feststoffgrundschicht in der Trommel veranlaßt die bereits abgesetzten Feststoffteilchen, entlang dem schraubenförmigen Schneckenkanal zum Wehr zu wandern, wo sie dann mit dem Zentrat aus dem Rotor gespült werden.

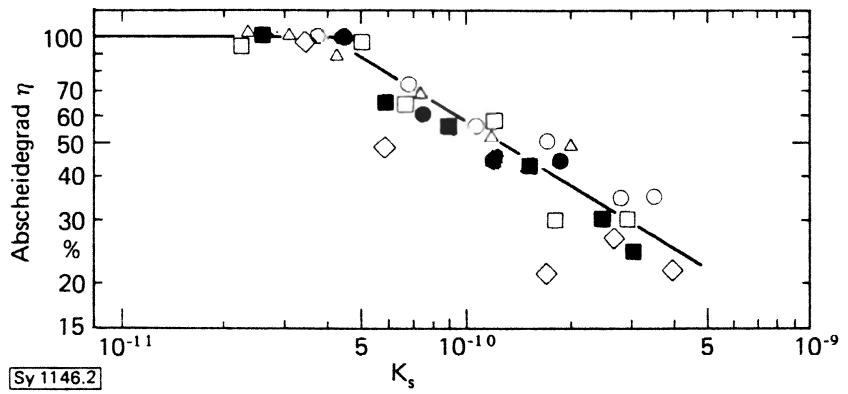

Abb. 2. Der Abscheidegrad als Funktion der Kennzahl $K_{\mathrm{s}}$.

\begin{tabular}{|c|c|c|c|c|c|c|}
\hline \multirow[b]{2}{*}{ Symbol } & \multicolumn{5}{|c|}{ große Maschine } & \multirow{2}{*}{$\begin{array}{c}\text { kleine } \\
\text { Masch. } \\
\triangle\end{array}$} \\
\hline & $\square$ & $\bigcirc$ & $\bullet$ & $\mathbf{\square}$ & $\diamond$ & \\
\hline$C$-Wert & 1000 & 1000 & 1000 & 700 & 500 & 1000 \\
\hline $\begin{array}{l}\text { Differenz- } \\
\text { drehzahl }[1 / \mathrm{min}]\end{array}$ & 20 & 15 & 15 & 20 & 20 & 20,8 \\
\hline Niveau $[\mathrm{mm}]$ & 90 & 65 & 100 & 90 & 90 & 30 \\
\hline
\end{tabular}

An einem bereits abgesetzten Teilchen greifen folgende Kräfte an (Schleppkraftansatz):

Anpreßkraft $\quad F_{\mathrm{A}}=\frac{\pi}{6} x^{3} \Delta \varrho g C$,

Reibungskraft $\quad F_{\mathrm{H}}=f F_{\mathrm{A}}$,

Schleppkraft $\quad F_{\mathrm{s}}=\frac{\pi}{4} x^{2} \eta x$.

Unter der Annahme einer laminar ausgebildeten ebenen Schichtströmung erhält man für den Durchsatz:

$Q=f \frac{2}{9} g C \frac{\Delta \underline{Q}}{\eta} x_{\mathrm{s}} h_{\mathrm{Niv}}^{2} b_{\mathrm{k}}$

Aus Abb. 2 sieht man, daß sich für die Beurteilung verschiedener Maschineneinstellungen und Maschinen die aus dem Schleppkraftansatz gefolgerte Kennzahl

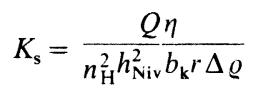

eignet. Eine analoge Auftragung nach der Theorie der äquivalenten Klärfläche ergibt keine Normierung der Versuchsergebnisse auf eine einzige Kurve.

Nimmt man für zwei verschieden große Maschinen die gleiche Zentrifugalbeschleunigung an, so erhält man aus Gl. (6) für die Umrechnung der Durchsätze:

$Q_{\text {Haupt }}=i^{3} Q_{\text {Pilot }}$.

Diese Abhängigkeit wurde in der Praxis vielfach gemessen. Es zeigt sich, daß die Abscheidung nicht nur von der Sedimentation, sondern 
auch vom Wegschleppen bereits abgesetzter Teilchen abhängt. Bei der Auslegung einer Dekantierzentrifuge mit Hilfe der Ergebnisse einer Pilot-Maschine muß daher die Gültigkeit beider Gesetze überprüft werden. Ein mögliches Verfahren wird in der Langfassung dieses Beitrages ausführlich beschrieben

Zusätzlich werden noch die Auswirkung der Schleppwirkung auf die Investitionskosten für Klärdekanter dargestellt und maschinentechnische Folgerungen gezogen.

Eingegangen am 23. November 1982

\begin{tabular}{|c|c|c|}
\hline$b_{\mathrm{k}}$ & {$[\mathrm{m}]$} & $\begin{array}{l}\text { Schneckenkanalbreite } \\
\text { Schleuderziffer }\end{array}$ \\
\hline$f$ & & Reibwert \\
\hline$g$ & {$\left[\mathrm{~m} / \mathrm{s}^{2}\right]$} & Erdbeschleunigung \\
\hline$h_{\mathrm{Niv}}$ & {$[\mathrm{m}]$} & Niveauhöhe \\
\hline$i$ & & Stufensprung \\
\hline$K_{\mathrm{s}}$ & {$[\mathrm{m}]$} & Kennzahl \\
\hline$L_{\mathrm{e}}$ & {$[\mathrm{m}]$} & effektive Klärlänge \\
\hline$n_{\mathrm{H}}$ & [U/min] & Hauptdrehzahl \\
\hline$r$ & {$[\mathrm{~m}]$} & Trommelradius \\
\hline
\end{tabular}

$\begin{array}{lll}r_{\mathrm{m}} & {[\mathrm{m}]} & \text { mittlerer Trommelradius } \\ Q & {\left[\mathrm{~m}^{3} / \mathrm{h}\right]} & \text { Durchsatz } \\ x_{\mathrm{G}} & {[\mathrm{m}]} & \text { Grenzkorndurchmesser } \\ x_{\mathrm{s}} & {[\mathrm{m}]} & \text { Schleppkorndurchmesser } \\ \eta & {[\mathrm{kg} / \mathrm{ms}]} & \text { dynamische Viskosität } \\ \chi & {[1 / \mathrm{s}]} & \text { Schergradient } \\ \Delta \varrho & {\left[\mathrm{kg} / \mathrm{m}^{3}\right]} & \text { Dichtedifferenz }\end{array}$

[1] Smith, F. H.; Hebb, M. H., in: Encyclopedia of Chemical Technology (Kirk, Othmer), Bd. 3, S. 501/521, Interscience, New York 1949

[2] Müller, H. W.; Schäffer, J.; Conrad, S.: Chem. Tech. (Leipzig) 32 (1980) Nr. 2, S. 76/80.

Schlüsselworte: Dekantierzentrifugen, Klärung, Scale-up.

Das vollständige Manuskript dieser Arbeit umfaßt 49 Seiten mit 25 Abbildungen, 2 Tabellen und 17 Literaturzitaten. Es ist als Fotokopie oder Mikrofiche MS 1094/83 erhältlich. Eine Bestellkarte finden Sie am Schluß dieses Heftes.
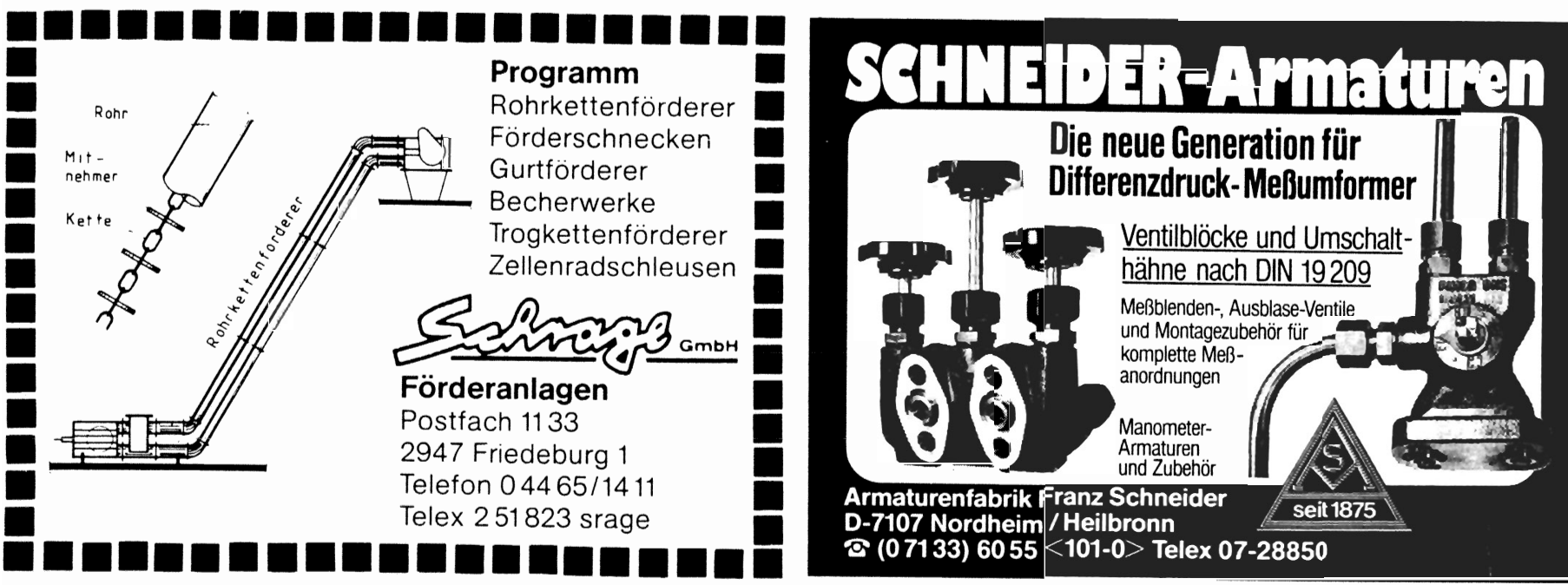

\section{DISPERGIEREN $\cdot$ KNETEN $\cdot$ RÜHREN mit IKA}

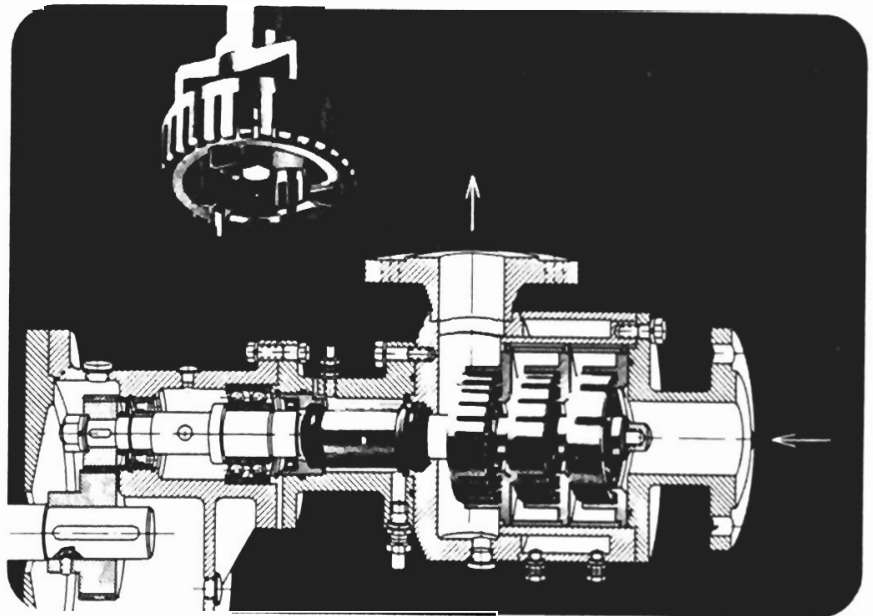

\section{ULTRA-TURRAX ${ }^{\circledR}$ - DISPAX-REACTOR ${ }^{\circledR}$}

International zwei feste Begriffe zur Lösung von Dispergierproblemen. Die kompletten Typenreihen für alle verfahrenstechnischen Aufgaben resultieren aus jahrzehntelangen Erfahrungen.

Durch komplexes Zusammenwirken mehrerer Zerkleinerungsmechanismen wird hervorragende Feinverteilung in allen dispersen Systemen erreicht.

\section{Homogenisieren · Emulgieren - Suspendieren}

Maschinengrößen für Chargen bis 6 to, kontinuierlich bis 80 to

ausgereifte Technik

geringer Energiebedarf

große Flexibilität

hohe Wirtschaftlichkeit

Verlangen Sie auch Prospekte über ULTRA-TURRAX ${ }^{\circledR}$-Anlagen und IKA-TURBOTRON ${ }^{*}$-Rührmaschinen 
Zur Werbesserung der Klärung in Dekantiexzentrifugen*

Werner Stahl, Thomas tangeloh*

\section{Zusamnenfassung}

"ur Auslegung von Dekantierzentrifugen steht von der theoretischen Seite bisher im Prinzip nur das auf das Fliehkraftfeld übertragene stokessche Gesetz zur Verfügung. Dies berücksichtigt nur pauschal die Klärfläche des Dekanters; andere Auslegungsdaten des Rotors, wie z.B. die Geometrie der Schnecke oder die Einstellung der Teichtiefe werden dabei nicht berücksichtigt.

Ein besseres Verständnis der Wirkung verschiedenex Maschineneinstellungen auf die klärung im Dekanter und eine sehr gute übereinstimmung mit einer einfachen Theorie erhält man dann, wenn man davon ausgeht, dab suspensionspartikel zwar nach der Beschreibung des stokesschen Gesetzes sedimentieren, sie jedoch in dem aus der Schnekkenwendel gebildeten strömungskanal am Boden nicht liegen bleiben, sondern durch das abströmende Zentrat zum ủberlauf gespült werden.

* Vortrag gehalten auf der Jahrestagung der Verfahrensingenieure in Basel am 1. Oktober 1982

* Prof. Dr.-Ing. Werner Stahl (Vortragender) und Dipl.-Ing. Thomas Langeloh Institut für Mechanische Verfahrenstechnik und Mechanik der Universitä Karlsruhe $(T H)$. Kaiserstr. 12, D-7500 Karlsruhe 
1. Einleitung und Wissensstand aus Theorie und Praxis

Bekanntich werden Dekantierzentrifugen für den Fall, daB die Feststoffaichte grober al= die Fiüssigkeitsdichte ist, in vielen Bra.ichen für die unterschiedichsten Fest-Flüssig-Trennaufgaben eingesetzt. Einer der Gründe dafür dürtte neben der für den Einsatzfall jeweils im Vergleich $z u$ anderen Lösungen nachzuweisenden wirtschaftlichkeit das weitgehend stabile Betriebsverhalten der Maschine sein; Schwankungen des zulaufs bezüglich Kornverteilung, Feststoffkonzentration, Zähigkeit u.a. werden von der Maschine "angenommen", es ändern sich lediglich die Trennergebnisse in monotoner Weise. Ein mögliches Betriebsversagen wie es z.B. die Schubzentrifuge bei schichtdurchbruch zeigt, tritt beim Dekanter nicht auf.

Über die verfahrenstechnische Auslegung wurde von vielen Autoren berichtet, sowohl für die Seite der Feststoffentfeuchtung $|1,2|$ als auch über die Klärung des Zentrats $|3,4,5,6,8,9,10|$. Ohne an dieser stelle auf die einzelnen Beiträge einzugehen, muB man leider feststellen, daB die auf der Theorie der äquivalenten Klärfläche aufbauenden Berechnungsmethoden zur Vorhersage des Feststoffgehalts im zentrat in keiner weise ! allein ausreichen, um Auslegungen für indu- strielle Zwecke zu treffen.

Dies gilt einerseits für die rein analytische Vorgehensweise, bei der man versucht, aus den Produktdaten (Zähigkeit, Dichteunterschied und Partikelverteilung) im zusammenwirken mit den konstruktiv festgelegten Maschinenwerten (Durch- 
messer und Klärlänge, a.h. der Klärfläche) und den Maschineneinstellwerten (Drehzahl, Differenzarehzahl, Niveauhöhe) das Klärergebnis vorherzusagen. Andererseits trifft es aber leider auch noch weitgehend auf die mehr ingesieurmäBige Vorgehensweise zu, nämlich die Ubertragung von tatsächlich gemessenen Trennergebnissen eines Pilotdekanters mit Hilfe von Ahnlichkeitsgesetzen auf eine anvisierte Grobausfühung.

Die einzige bis heute angewandte Theorie zur Berechnung der Klärung ist bekanntlich das auf das Fliehkraftfeld übertragene Stokessche Gesetz; es beschreibt für den laminaren Bereich die sedimentation eines starren kugelförmigen Einzelteilchens in einer ruhenden Newtonschen Flüssigkeit.

Gegenüber der technischen Realität im Dekanter unterscheidet sich dieser vereinfachte Modellfall duch folgende Einflüsse, die sich in zwei Gruppen einteilen lassen:

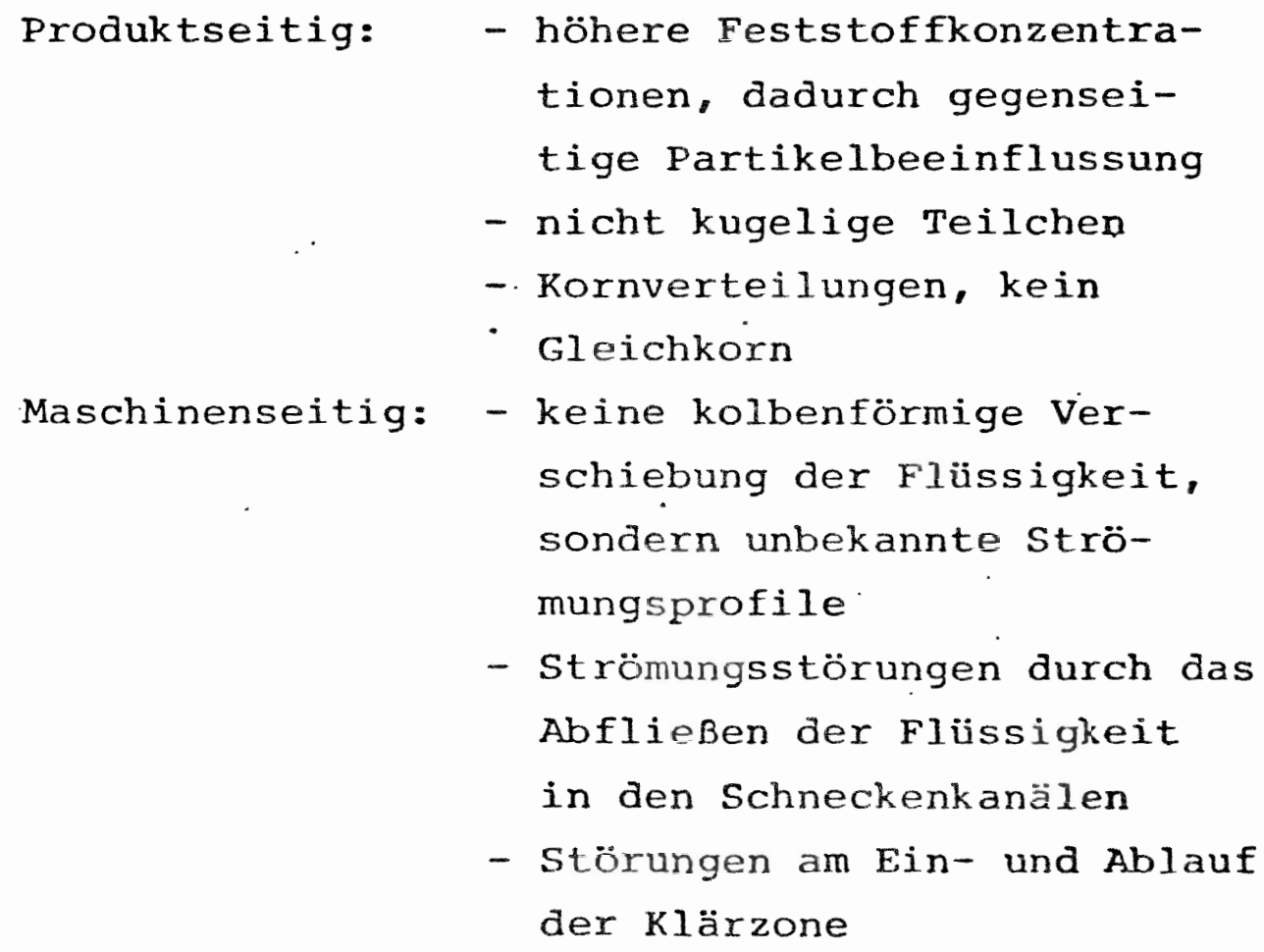
schiebung der Flüssigkeit, sondern unbekannte strömungsprofile

- Strömungsstörungen durch das Abflieben der Flüssigkeit in den Schneckenkanälen

- Störungen am Ein- und Ablauf der Klärzone 
- Wirkung von Differenzdrehzahl una querschnittsverminderndem sedimentiertem kuchen, u.a.m.

Viele Autoren haben das stokessche casetz für die Beschreibung der realen Vorgänge im Dekanter durch Einfüren von korrekturfaktoren an die MeBwerte angepabt. Ohne aber diese Bemühungen abzuwerten, ist doch festzustellen, daB der Wissensstand unbefriedigend ist und daB mit diesem Gesetz viele Erscheinungen nicht zu erklären sind.

Dies wird am deutlichsten, wenn man das aus dieser Theorie hergeleitete Scale-up Gesetz auf seine Leistungsfähigkeit hin überprüft. Vernachlässigt man die verschiedenen Korrekturfaktoren - sie müssen bei ähnlich größer ausgeführtem Dekanter konstant bleiben - so lautet der schon von $|3|$ angegebene Zusammenhang zwischen Durchsatz, noch zulässiger Partikelgröße im zentrat und den Maschinendaten:

$Q=\frac{4 \pi^{3}}{9} \cdot \frac{\Delta \rho}{\eta} \cdot x_{G}^{2} \cdot n_{H}^{2} \cdot L_{e^{\cdot}}\left(r_{T}-\frac{h_{N i v}}{2}\right)^{2}$

Halten wir die Produktdaten konstant und fragen nur nach dem EinfluB der-Geometrie-einer un den. Stufensprung $i$ gröBeren Maschine, so ergibt sich daraus durch Verhältnisbildung:

$\frac{Q_{\text {Haupt }}}{Q_{\text {Modell }}}=\frac{n_{\text {Haupt }}^{2}}{n_{\text {Modell }}^{2}} \cdot \frac{L_{e_{\text {Haupt }}}}{L_{e_{\text {Modell }}}} \cdot \frac{\left(r_{T}-\frac{h_{N i v}}{2}\right)_{\text {Haupt }}}{\left(r_{T}-\frac{h_{N i v}}{2}\right)_{\text {Modell }}^{2}}$

$$
=\frac{n_{\text {Haupt }}^{2}}{n_{\text {Model } 1}^{2}} \cdot i \cdot i^{2}
$$


Bei gleicher Zentrifugalbeschleunigung beider Maschinen gilt für die Hauptarehzahlen

$\frac{n_{\text {Haupt }}^{2}}{n_{\text {Mode1 } 1}^{2}}=\frac{1}{i}$, da $\left(x \omega^{2}\right)_{\text {Mod }}=\left(r \omega^{2}\right)_{\text {Haupt }}$

In Wirklichkeit wird bei gleicher Ausnutzung der Festigkeit beider Rotoren nicht die Beschleunigung sondern die Rotorumfangsgeschwindigkeit konstant gehalten. Da die Umfangsspannung im Rotor der Umfangsgeschwindigkeit proportional ist, also u $\sim r . n=$ konst, gilt

$\frac{{ }^{n} \text { Haupt }}{n_{\text {Mode11 }}}=\frac{1}{i}$

Korrigiert man die obigen Durchsatzverhältnisse entsprechend, so folgt

$\frac{Q_{\text {Haupt }}}{Q_{\text {Modell }}}=\frac{i^{3}}{i}=i^{2}$ bzw $\cdot \frac{Q_{\text {Haupt }}}{Q_{\text {Modell }}}=i$

je nachdem, ob man den Modellversuch bei gleicher Zentrifugalbeschleunigung oder bei gleicher Umfangsgeschwindigkeit des Rotors angesetzt hatte.

Diese Beziehung steht im widerspruch zu vielen Ergebnissen der Praxis, wonach-bei gleicher Beschleunigungsziffer eine Kapazitätserhöhung mit der 3. Potenz des Durchmessers bei ähnlichen Maschinen beobachtet wurde.

Ein weiteres Ergebnis, das man bei der Anwendung des Stokesschen Gesetzes auf die Vollmantelschneckenzentrifuge erhält, stimmt nachdenklich: Die Niveauhöhe geht nicht in die Kapazität der Maschine ein; sie kann beim Ansatz dieser 
Theorie herausgekürzt werden.

Aus der Praxis ist aber die starke Abhängigkeit dex Niveauhöhe auf die Durchsatzleistung bekannt. Fast alle Hersteller haben aus aieser bekannten Tatsache den SchluB gezogen, den Kours mit geringem Austragsdurchmesser zu bauen, so daB hohe Niveaveinstellungen gefahren werden können.

Wenden wir uns nach djeser Rückschau auf bekannte Diskrepanzen neuerer Uberlegungen $z u$.

\section{Experimentelle Untersuchungen}

Aus einer großen Zahl von Versuchen mit Dekantern verschiedenster Größen und mit verschiedensten produkten ist folgendes, in leichten Variationen immer wiederkehrendes, Klärverhalten beobachtet worden (Abb. 1).

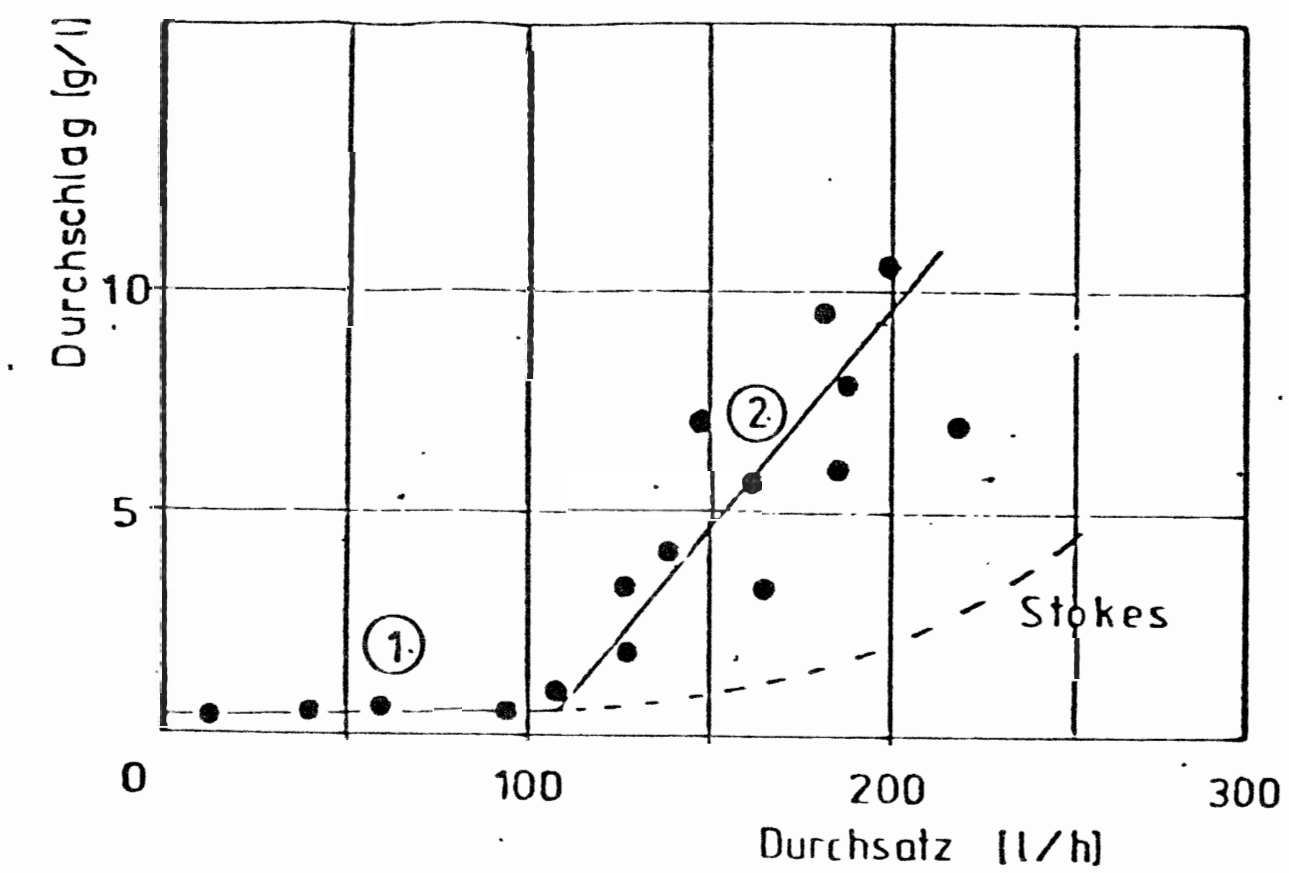

Abb. 1. Der Durchschlag als Funktion des Durchsatzes 
Der Feststoffgehalt steigt über dem suspensionsdurchsatz bei konstant gehaltenen Maschinenparametern zunächst monoton an. Die Kurve kann dabei aus dem Nullpunkt herauslaufen, sie kann aber auch bereits bei einem geringen Feststoffdurchschlag beginnen. Der Grenzwert des Feststoffgehalts bei $Q \rightarrow 0$ kann nicht gemessen werden; man bestimmt ihn durch Rückextrapolation. Die MeBwerte in diesem ersten Bereich (1) streuen gering; sie sind nach einer wartezeit, die etwa dern 10 fachen der Flüssigkeitsaufenthaltszeit im Rotor entspricht, konstant geworden. Die Werte sind auch bei steigerung und Verminderung des Durchsatzes gut reproduzierbar.

Der Feststoffgehalt im Zentrat bei sehr kleinen Durchsätzen konnte in vielen Fällen eindeutig auf den EinfluB der Differenzdrehzahl zurückgeführt werden. Rückt man den überlastschutz der Maschine aus - die schnecke hat jetzt die gleiche Drehzahl wie die Trommel - so miBt man für einige Zeit einen niedrigeren Durchschlag, der später natürlich mit steigender Feststoffüllung des Rotors ansteigt. Auf diese Weise kann man sich eine Vorstellung vom störeinfluB der Schneckenbewegung verschaffen, wenn dieses Ausrückeri der Schnecke bei verschiedenen Durchsätzen durchgeführt wird (Abb. 2). 


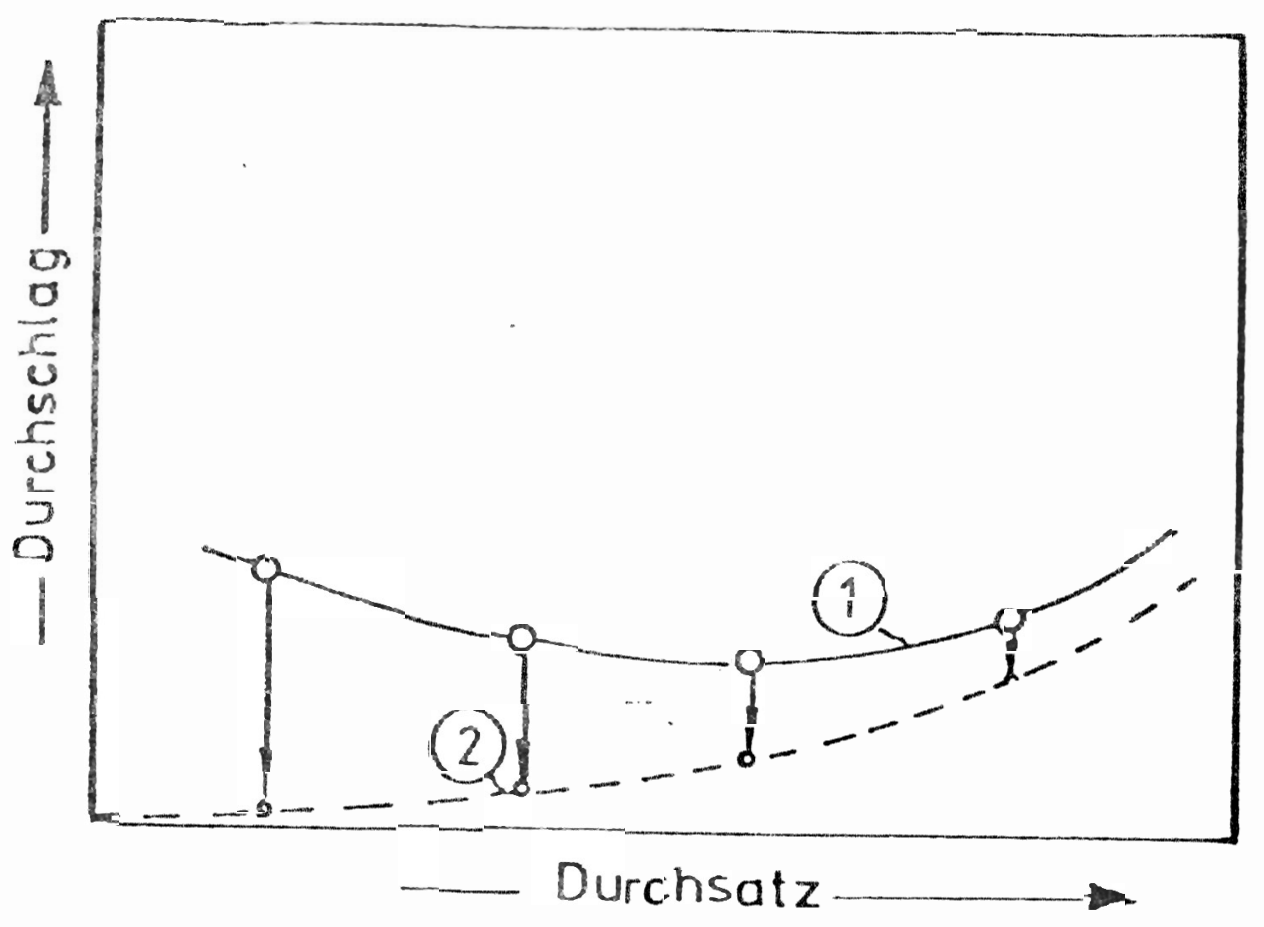

Abb. 2. Der Durchschlag als Funktion des Durchsatzes

1. Kontinuierliche Fahrweise

2. Punktweise erhaltene Kurve durch Abschalten des Überlastschutzes

$\mathrm{Ab}$ einem gewissen, sehr gut reproduzierbaren höheren Durchsatz - in zukunft $Q_{\text {krit }}$ genannt geht die Kurve in $\mathrm{Abb}$. 1 mit einem ausgeprägten Knick nach oben, wobei je nach Produkt Anstiege des Feststoffgehalts von ein bis zwei Zehnerpotenzen bereits bei $Q=1,1-1,5 Q_{k r i t}$ beobachtet werden (Bereich. 2). Es fällt ferner auf, daB die MeBwerte jenseits des kritischen Durchsatzes häufig stark streuen, was aber wegen der bei geringen Durchsätzen demonstrierten Genauigkeit nicht als MeBfehler abgetan werden kann. Die Meßwerte liegen häufig zwischen zwei scherenförmig auf den Punkt des kritischen Durchsatzes zulaufenden Geraden (siehe Abb. 1).

Bei einigen Versuchen zeigte sich, daB nahe am kritischen Durchsatz ein Hystereseverhalten zu existieren scheint: Bei sehr langsam erhöhten Durchsätzen ergaben sich manchmal gute Klärer- 
gebrisse noch jenseits des $Q_{\text {krit }}$-Punktes, der dadurch häufig durch Rückextrapolation genauer festgelegt werden konnte als durch direkte Messung (Abb. 3 ).

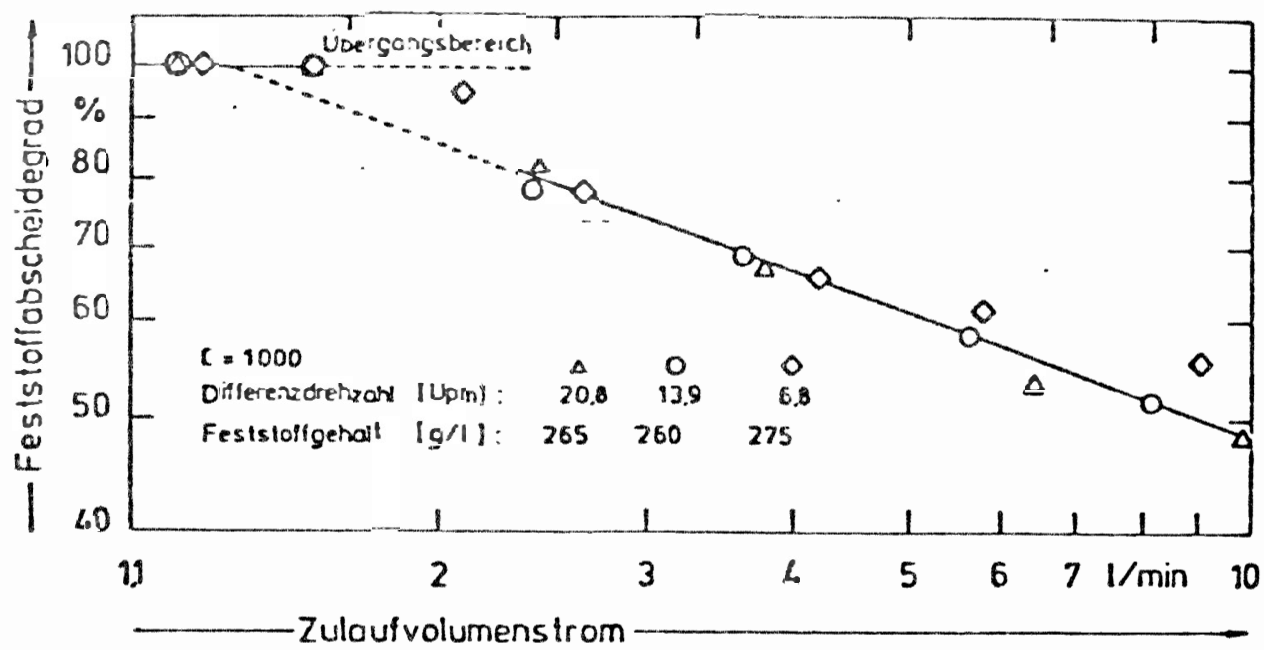

Abb. 3. Undeutlich ausgeprägter Knickpunkt; Fixierung durch Rückextrapolation

Dieser knickartige Verlauf des Feststoffgehalts ist nicht durch den Verlauf der nach dem Stokes.schen Gesetz für verschiedene Durchsätze berechneten GrenzkorngröBe zu erklären (Abb. 16a, 16b).

Der beobachtete Effekt ist für die technische Praxis besonders unangenehm, da festgelegte - Grenzwerte (Garantien) des Feststoffgehalts sofort un ein Vielfaches überschritten werden. 
Neben der zunächst nicht zu beantwortenden Frage nach der physikalischen Uxsache dieses Verhaltens, versucht man zunächst durch das Experiment folgende Fragestellungen zu beantworten:

In welcher Weise hängt die Lage des Knickpunkts von den frei veränderlichen Variablen Niveauhöhe, Haupt- und Differenzdrehzahl des Dekanters $a b$ ?

Der Knickpunkt konnte durch Niveauerhöhung ins Gebiet höherer Durchsätze verschoben werden, wobei der bereits bekannte steile Verlauf des zweiten Astes auf einem monoton höher ansteigenden Verlauf des Feststoffgehalts ansetzte (Abb. 4).

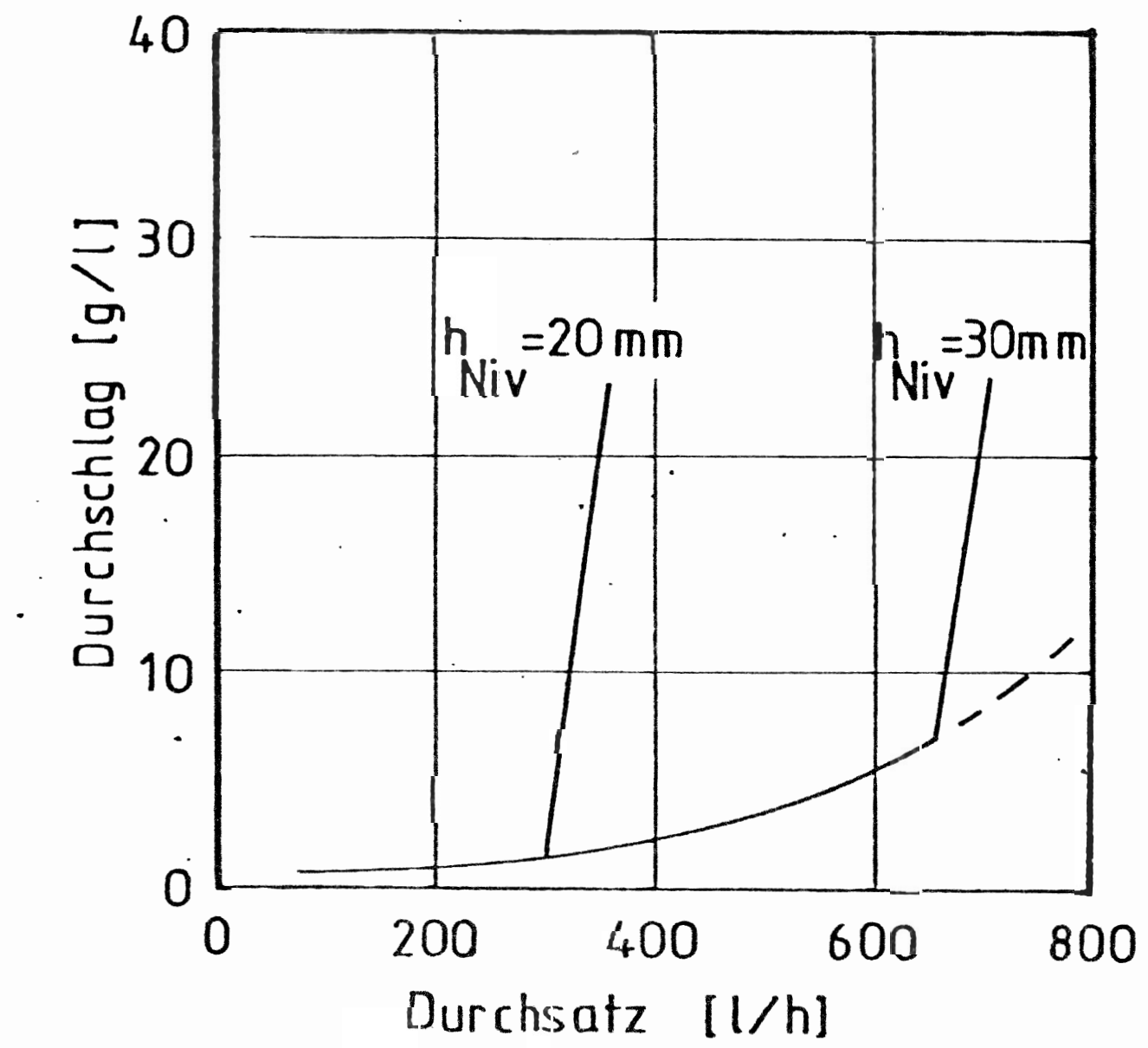

Abb. 4. Der Durchschlag als Funktion des Durchsatzes für zwei verschiedene Niveauhöhen (Kaolin) 
Aus eigenen Versuchen $|14,15|$ sowie einer Auswertung der Ergebnisse von $\mid 11$ - 13| konnte festgestellt werden, daB der Durchsatz $Q$ ungefähr proportional $\mathrm{zu} \mathrm{h} \mathrm{h}_{\mathrm{Niv}}^{2}$ ist (Abb. 5).

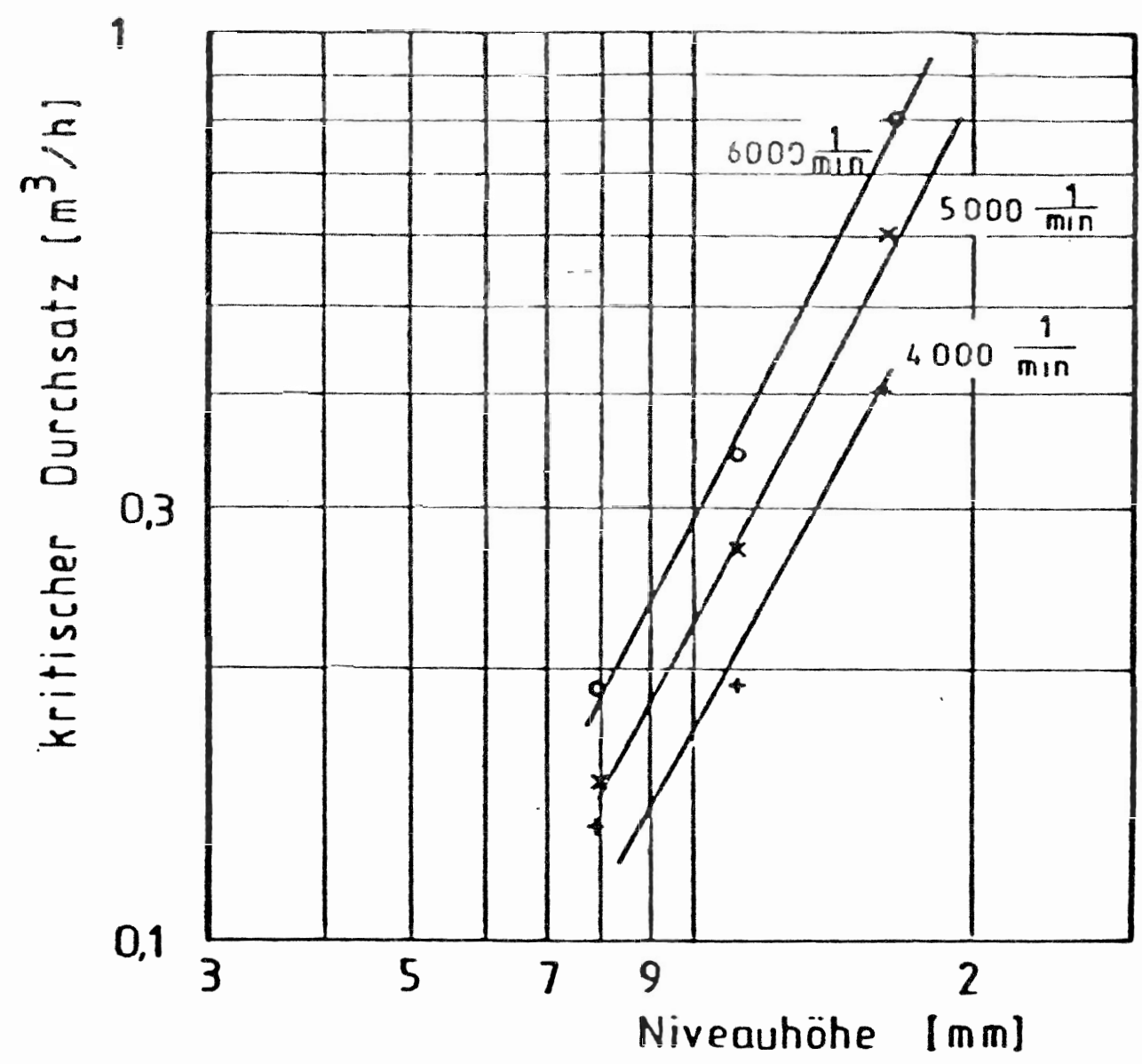

Abb. 5. Der kritische Durchsatz als Funktion der Niveauhöhe (D-Perlen; $|11|$ )

Die Abhängigkeit von der Hauptarehzahl ergab experimentell weniger präzise Ergebnisse. Der Exponent lag aber im Bereich von 2 oder kleiner (Abb. 6). 


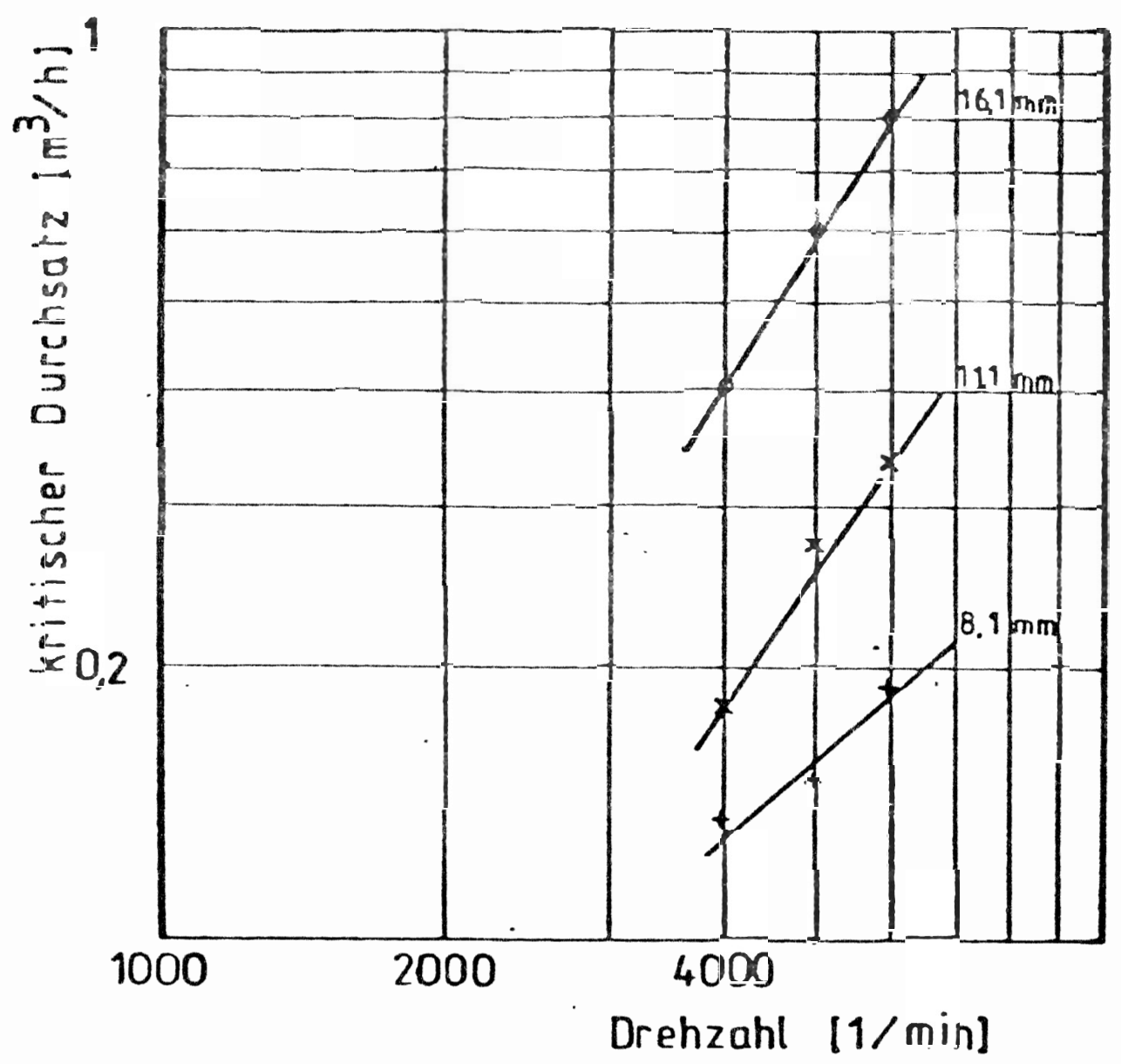

Abb. 6. Der kritische Durchsatz als Funktion der Hauptarehzahl (D-Perlen, $|11|$ )

Eine Abhängigkeit des kritischen Durchsatzes von der Differenzdrehzahl wurde nur dann festgestelit, wenn diese zu niedrig eingestellt war und damit ein Rückstau des Feststoffs in den Klärteil vorhanden war oder extrem hoch gewählt wurde, wie sie für Kläraufgaben in keinem Fall sinnvoll ist. 
Wie aus $\mathrm{Abb}$. $3 \mathrm{zu}$ sehen ist, hat die im Bereich 1:3 veränderte Differenzdrehzahl keinen EinfluB auf den Abscheidegrad.

Auch $|12|$ hat schon festgestellt - wie Abb. 7 zeigt - daß die Differenzdrehzahl die Lage des knickpunktes nicht zu verändern vermag.

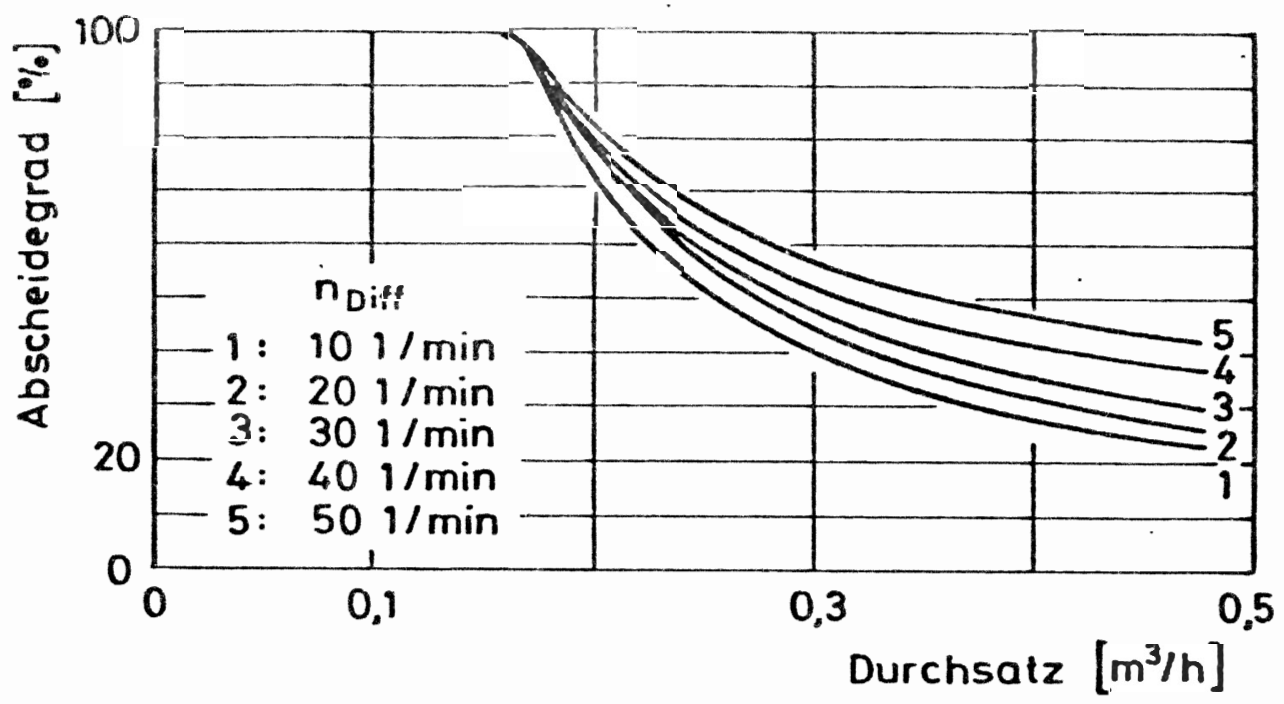

Abb. 7. EinfluB der Differenzdrehzahl auf die Klärung |12| 
Statt des Feststoffgehalts im Zentrat ist dort der daraus ableitbaxe Ausdruck des Abscheidegrades (Feststoffstrom im Zulauf minus Feststofistrom im Zentrat bezogen auf den Feststoffstrom im Zulauf) aufgetragen, der in der Aufbereitungstechnik auch häufig als Feststofiausbringen bezeichnet wird. Änderungen der Schnekkengeometrie wurden von den verfassern im Laufe dieser Untersuchungen aus Zeit- und Kostengründen noch nicht durchgeführt. Trotzdem konnte aufgrund der oben beschriebenen eigenen Ergebnisse, der Literaturauswertung und vieler anderer Exfahrungen, deren Beschreibung hier zu weit führen wïrde, eine vorstellung vom physikalischen Vorgang dieses unstetigkeitsbereichs aufgebaut werden.

\section{Der Schleppeffekt}

Das Vorhandensein einer Unstetigkeit im Klärverhalten von Gegenstromdekantern und ihre quantitative Abhängigkeit läBt den SchluB zu, daB sich dem normalen monoton schlechter werdenden $\mathrm{Ab}-$ scheideverhalten, das näherungsweise zumindest in Gebieten sehr kleiner Feststoffkonzentrationen durchaus durch das stokessche Gesetz mit den in der Literatur |8.- $10 \mid$ aufgeführten Korrektur- : faktoren beschrieben werden kann, ein anderer zusätzlicher Effekt überlagert und dieser, wenn er jenseits $Q_{\text {krit }}$ auftritt, dann das Geschehen völlig beherrscht. Dieses zweite Gesetz löst dann im Sinne einer Ja-Nein Entscheidung das modifizierte Stokessche Gesetz ab.

Es besteht folgende Vorstellung:

Die mit zunehmendem Durchsatz steigende Schubspannung in der Flüssigkeit auf der oberfläche 
der Feststoffgrundschicht veranlaBt die bereits abgesetzen Feststoffteilchen zun Wandern. Sie werden durch den aus den schneckengängen gebildeten Strömungskanal in spiraliger Richtung mit der Flüssigkeit mitgeschleppt und über das wehr am Ende des Rotors mit ausgetragen.

Dieses Gleiten oder Rollen der Teilchen auf der Oberfläche der Feststoffgrundschicht in der Trommel ist ein Vorgang, der sowohl von der Teilchengröße und -form, der Zähigkeit der Flüssigkeit, natürlich vom Strömungsprofil, aber auch von Unwägbarkeiten, wie dem Verschleibzustand der Schnecke und dem damit verbundenen Profil der in die Grundschicht eingedrehten Riefen abhängt.

Ein ähnlicher Vorgang des MitreiBens abgesetzter Teilchen kommt in der Natur in jedem Flubbett vor. Die Schleppwirkung verschwindet und es tritt beruhigtes Absetzen auf, wenn die Strömungsgeschwindigkeit des Flusses sinkt; dies ist bei der Mündung ins Meer $\mathrm{zu}$ beobachten und führt zur bekannten Deltabildung.

\section{Der Rechnungsansatz für den Schleppeffekt}

Obwohl dieser Vorgang im Dekanter in Betriebszuständen mit erheblichem Feststoffgehalt im Zentrat sicher als strähnenförmiges MitreiBen von Partikelscharen vorzustellen ist, in denen auch eine Wechselwirkung der Teilchen untereinander auftritt, erscheint es doch berechtigt, für eine erste mathematische Formulierung dieses Vorgangs einige Vereinfachungen zu treffen. Wir nehmen an, daß ein einzelnes kugelförmiges Partikel in einer ausgebildeten laminaren strömung auf der Innenoberfläche einer mit einer Produkt- 
grundschicht überzogenen Trommel liegt und der zentratströmung im schneckenkanal ausgesetzt ist.

Da es im Folgenden nicht vorrangig. darum geht, Aussagen über den Abscheidegrad im Gebiet $Q>Q_{k r i t} z u$ machen, sondern gerade den Grenzfall $Q_{k r i t}$ zu lokalisieren, ist die vereinfachte Annahme, daB gerade einige wenige Teilchen nahe dem Utberlaufende des Dekanters abgespült werden, sicher gerechtfertigt.

Abb. 8 zeigt die Kräfteverhältnisse an diesem Teilchen. Es wird mit der AnpreBkraft $F_{A}$ auf die Unterlage gepreßt.

$F_{A}=\frac{\pi}{6} x^{3} \cdot \Delta \rho \cdot g \cdot C$

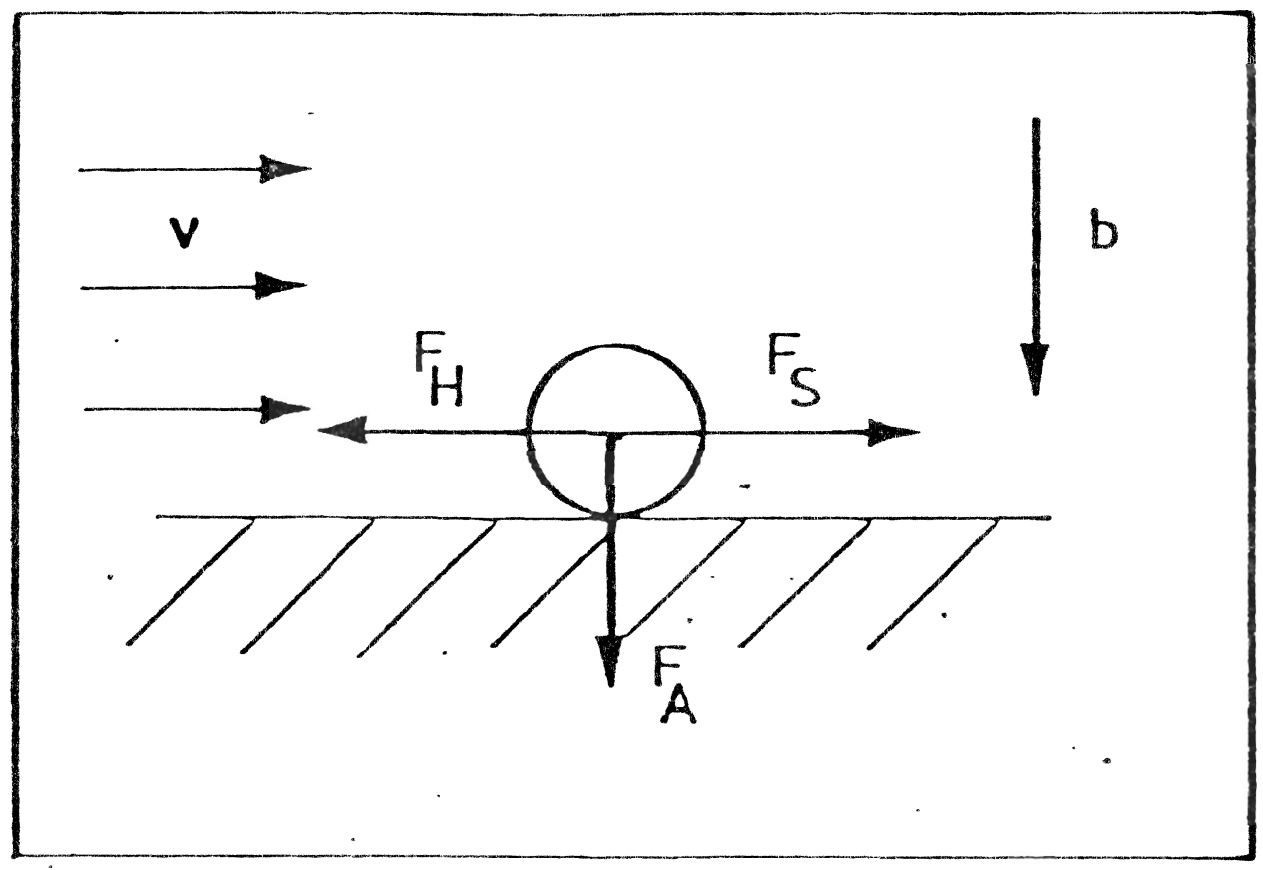

Abb. 8. Kräftebilanz an einem bereits abgesetzten Teilchen (Schleppkraftansatz) 
Zwischen Teilchen und Unterlage herische eine der Gleit- oder Kollbewegung entgegengerichtete Reibungskraft $F_{H^{*}}$ die-der Einfachheit halber nach dem Coulombschen Reibungsgesetz als proportional zur AnpreBkraft angenommen wird.

$F_{H}=f \cdot F_{A}$

Für die Schleppkraft auf einlliegendes kugeliges Teilchen in einer scherströmung gilt:

$$
\begin{aligned}
& \mathrm{F}_{\mathrm{s}}=\frac{\pi}{4} \cdot \mathrm{x}^{2} \quad \cdot \quad \cdot \mathrm{r}_{\mathrm{r}} \quad \cdot \quad \mathrm{k} \\
& \text { Anströmfläche Viskosität Scherge- } \\
& \text { d. Teilchens d.Flüssig- fälle } \\
& \text { keit }\left(\frac{d u}{d z}\right)
\end{aligned}
$$

Eine Beziehung zwischen dem Zentratdurchsatz des Dekanters und dem Schergefälle am Boden ergibt sich unter Annahme einer laminaren ausgebildeten ebenen Schichtströmung (Parabelprofil) zu

$\kappa=\left(\frac{d u}{d z}\right)_{z=0}=\frac{3 \cdot v_{m}}{h_{N i v}}=\frac{3 \cdot Q_{\text {Zentrat }}}{h_{N i v} \cdot h_{N i v} \cdot b_{K}}$

Aus der Skizze (Abb. 9) wird deutlich, daB sich die Kanalbreite aus den Schneckendaten ergibt zu:

$b_{K}=G \cdot \cos \alpha-z_{S} \cdot d_{S}$

damit wird

$$
k=\frac{3 \cdot Q}{h_{N i v}^{2} \cdot\left(G \cos \alpha-z_{s} \cdot d_{s}\right)}
$$

Setzt man diesen Ausdruck jetzt in das obige Kräftegleichgewicht fur die Horizontalrichtung ein, so folgt: 


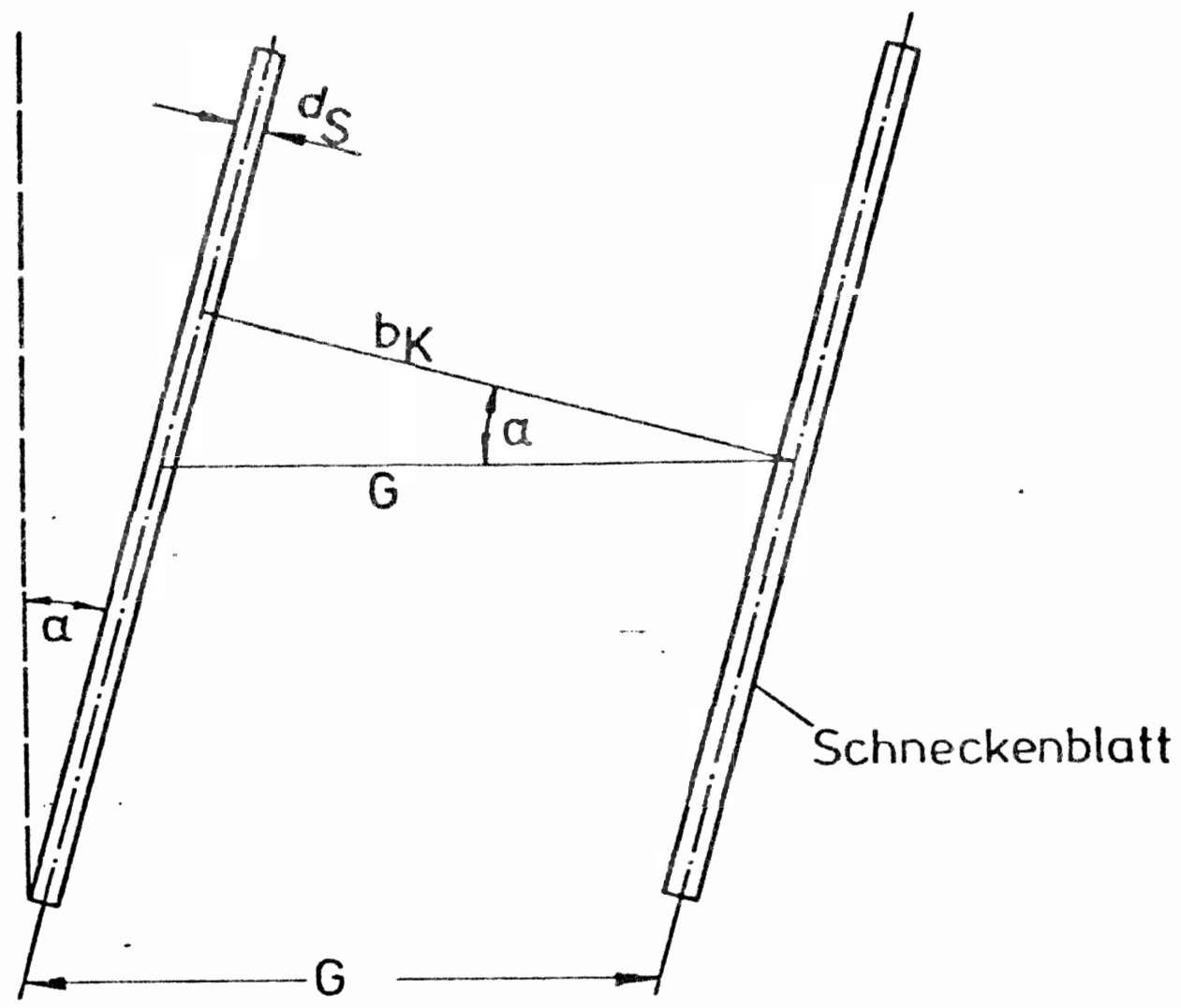

Abb. 9. Der Zusammenhang zwischen Kanalbreite und Schneckengeometrie

$$
\begin{aligned}
& F_{H}=F_{S} \\
& f \cdot \frac{\pi}{6} \cdot x^{3} \cdot \Delta \rho \cdot g \cdot C=\frac{\pi}{4} \cdot x^{2} \cdot n \cdot \frac{3 \cdot Q_{\text {Zentrat }}}{h_{N i v}^{2}\left(G \cdot \cos \alpha-z_{s}{ }^{\prime} s^{\prime}\right.} \\
& Q_{\text {Zentrat }}=f \cdot \frac{2}{9} \cdot g \cdot C \cdot \frac{\Delta \rho}{n} \cdot x \cdot h_{N i v}^{2}\left(G \cdot \cos \alpha-z_{s} d_{s}\right)
\end{aligned}
$$

Man kann diese Gleichung auch nach der Partikelgröße auflösen und erhält:

$$
x_{s}=\frac{Q_{\text {Zentrat }} \cdot 9 \cdot n}{\text { 2.f.g.C. } \Delta \rho h_{N i v}^{2}\left(G \cdot \cos -z_{s} d_{s}\right)}
$$

Die Schleppkorngröße gibt - wie der Grenzkorndurchmesser nàch dem Stokesschen Gesetz für die 
Sedimentation - an, welche Teilchen gerade noch auf der Grundschicht haften und welche Teilchen mit dem Zentrat aus der Maschine gespült werden.

Der Reibwert berechnet sich mit

$$
f=\frac{Q_{\text {Zentrat }} \cdot 9 \cdot \eta}{x_{s} \cdot 2 \cdot g \cdot C \cdot h_{N i v}^{2} \cdot\left(G \cdot \cos \alpha-z_{s} d_{s}\right) \cdot \Delta \rho}
$$

Die Gegenüberstellung der beiden Gesetze macht die Analogie deutlich:

$$
\begin{aligned}
& Q=\text { konst } \cdot \frac{\Delta \rho}{n} \cdot x_{G}^{2} \cdot c \cdot g \quad \cdot L_{e} \cdot\left(r_{T}-\frac{h N 1 v}{2}\right) \text { stokes } \\
& Q=\text { konst } \cdot f \cdot \frac{\Delta \rho}{n} \cdot x_{s} \cdot c \cdot g \quad \cdot h_{N 1 v}^{2}\left(G \cdot \cos a-z_{s} d_{s}\right) \text { schleppkraft }
\end{aligned}
$$

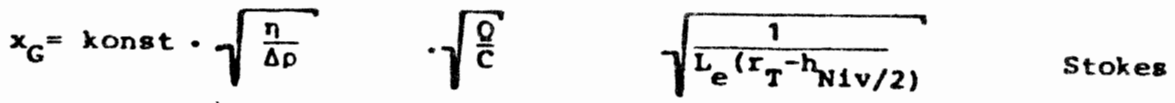

$$
\begin{aligned}
& x_{s}=\operatorname{konst} \cdot \frac{i}{f} \frac{\eta}{\Delta p} \quad \cdot \frac{Q}{C} \quad \cdot \frac{1}{h_{N i v}^{2}\left(G \cdot \cos \alpha-z_{g}^{d}\right)} \text { schleppkraft } \\
& \begin{array}{l}
\text { Produkt- Einstell- Maschinendaten } \\
\text { Caten }
\end{array}
\end{aligned}
$$

Wir müssen also mit zwei voneinander unabhängigen Grenzkorngrößen operieren, wobei die jeweils gröBere den Durchsatz limitiert.

Der Reibwert $f$ ist natürlich nicht analytisch durch Messung zu.ermitteln; er muB, falls nötig, aus einem Dekanterversuch bestimmt werden. In Verbindung mit der Kornverteilung der zulaufsuspension können nun folgende möglichen Betriebszustände auftreten:

- Ist $x_{\text {min }}<x_{s}<x_{G}$ bzw. $x_{\text {min }}<x_{G}<x_{s^{\prime}}$, dann ist der Abscheidegrad grundsätzlich schon 
kleinex als $100 \%$ (Abb. 10). Beim kritischen Durchsatz ist die Grenzkorngröße gleich der Schleppkorngröße, d.h. beide Gesetze gelten gleichzeitig. Für Durchsätze kleiner $Q_{k r i t}$ gilt das stokessche Gesetz und fir gröBere Durchsätze beschreibt der Schleppkraftansatz die Abscheidung.

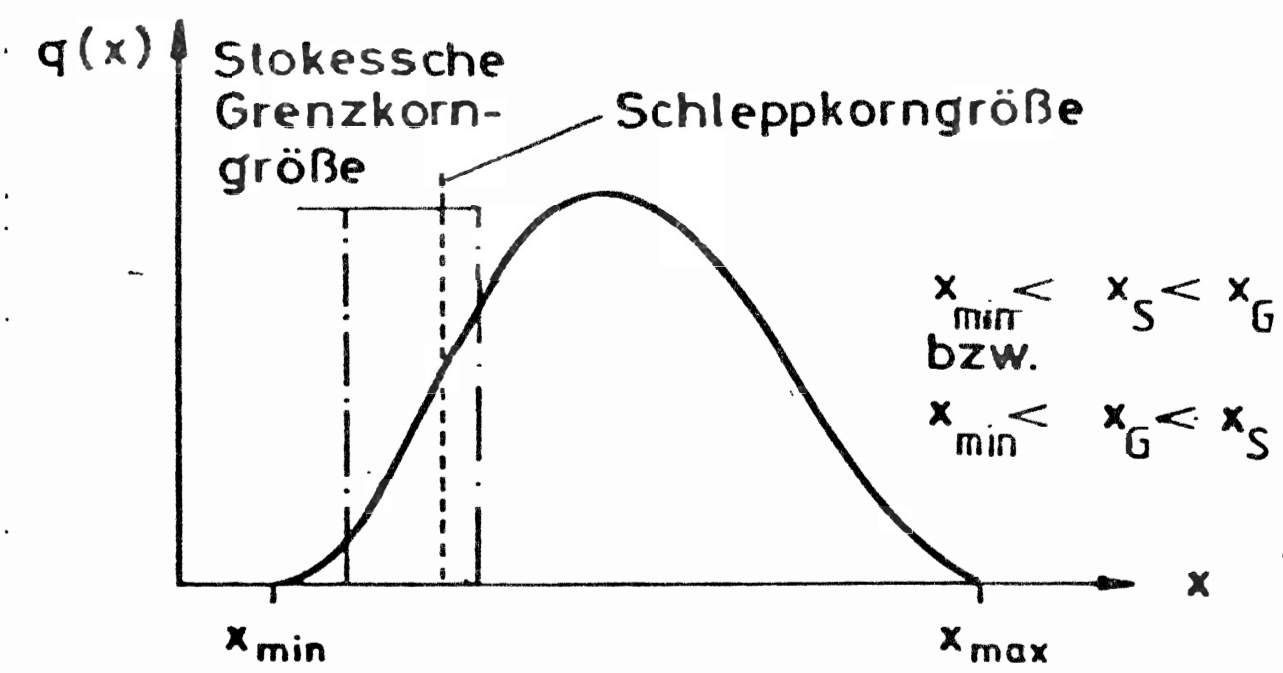

$\underline{A b b .}$ 10. $x_{\min }<x_{s}<x_{G}$ bzw. $x_{\min }<x_{G}<x_{S}$

Zur Bestimmung von $f$ kann man dann aus der Stokesschen Gleichung die PartikelgröBe ausrechnen und in die Gleichung (14) einsetzen. Dies setzt aber voraus, daB das stokessche Gesetz ohne Korxekturen die richtige Paxtikelgröße liefert. 
- Der zweite praktisch wichtigere Fall ist gegeben, wenn $x_{G}<x_{s}<x_{\text {min }}$ bzw. $x_{S}<x_{G}<x_{\min }$ (Abb. 11). Man hat dabei zunächst eine vollkommene Abscheidung, bis bei einer weiteren Durchsatzerhöhung $x_{s}$ gleich $x_{\min }$ bzw. $x_{G}=x_{\min }$ wird.

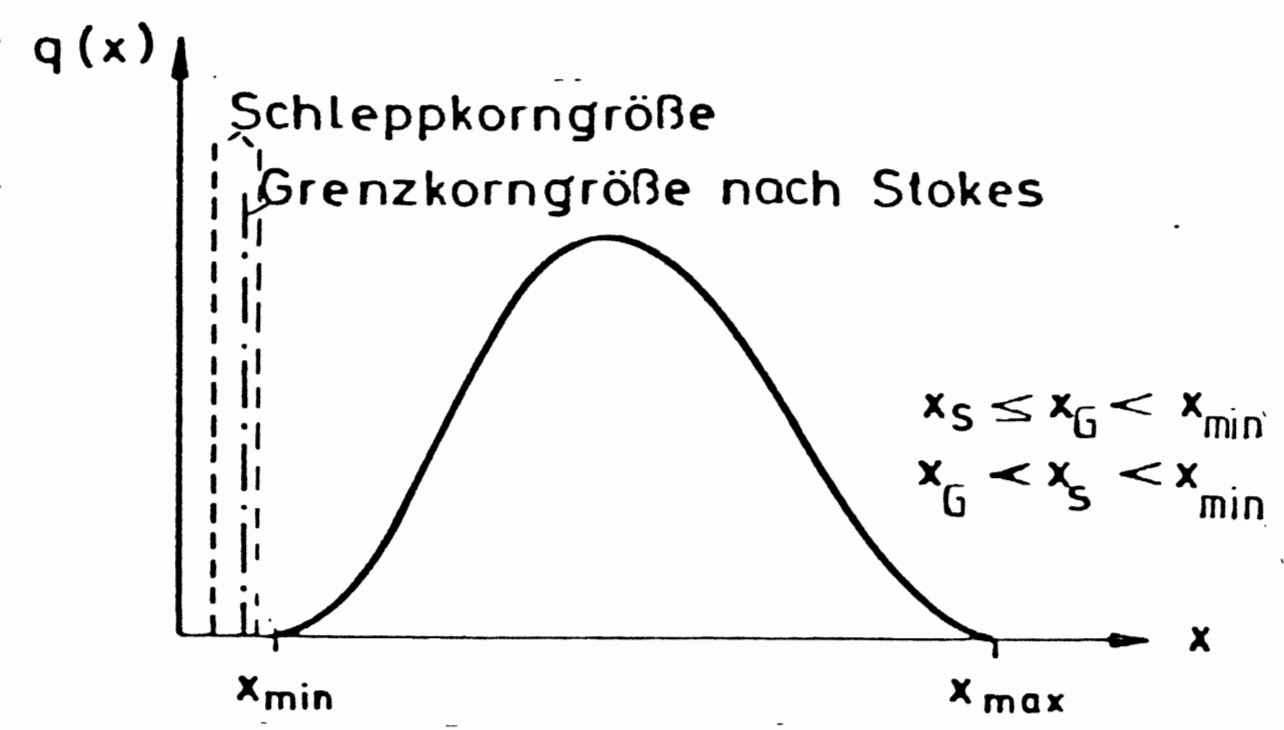

Abb. 11. $x_{S}<x_{G}<x_{\min } b z w$. $\mathrm{x}_{\mathrm{G}}<\mathrm{x}_{\mathrm{S}}<\mathrm{x}_{\min }$

Für den Fall, daB $x_{S}=x_{\text {min }}>x_{G}$ setzt man zur Berechnung des Reibwertes 1 mit Gleichung (14) fiir $Q$ den kritischen Durchsatz $Q_{k r i t}$ und für $x_{s}$ den kleinsten Partikeldurchmesser des Feststoffes $x_{\min }$ eïn $(A b b \cdot 12)$. In diesem Fall wird die Abscheidung nur durch den Schleppkraftansatz beschrieben. 


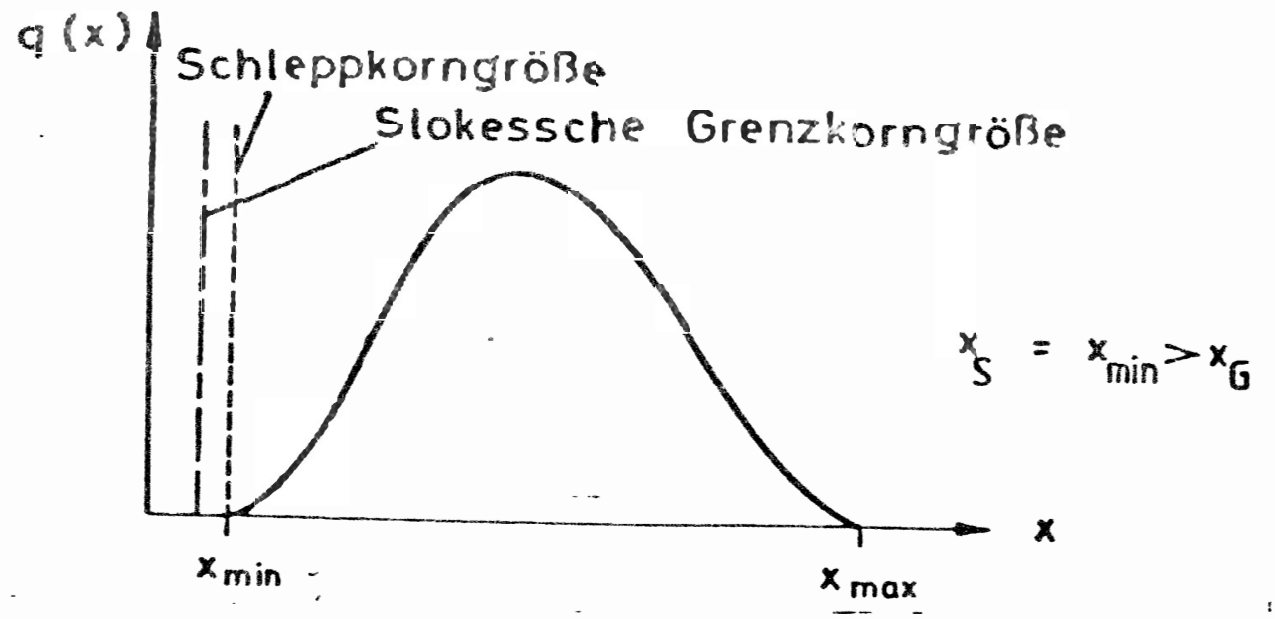

Abb. 12. $x_{s}=x_{\text {min }}>x_{G}$

Die Uberschneidung der-beiden Gesetze entsteht durch die unterschiedliche Abhängigkeit des Grenzkorndurchmessers $\left(x_{G} \sim \sqrt{Q}\right)$ und des Schleppkorndurchmessers $\left(x_{S} \sim Q\right)$ vom Durchsatz.

Von diesem Wissensstand aus lassen sich jetzt 5 wichtige Themenkreise gedanklich weiterverfolgen:

- Vergleich der Theorie mit den MeBergebnissen

- Versuch einer Vorhersage des Abscheidegrads für Bereiche $Q>Q_{k r i t}$

- Scale-up-Methoden bei Berücksichtigung dex Schleppwirkung

- Betriebstechnische Konsequenzen für den Einsatz von Dekantern 
- Konstruktive Konsequenzen für die konstrujtion von neven, und die Nachbesserurg von existenten Dekantern.

\section{Vergleich der Theorie mit den MeBergebnissen}

Setzt man sich als erstes Ziel, die Betriebseinstellungen eines einzigen Dekanters ineinander umrechnen zu können, so kann man diese Theorie überprüfen, indem man einen Kennwert

$\frac{Q}{n_{H}^{2} \cdot h_{N i V}^{2}}$

bildet. Dies zeigt nochmals $A b b$. 13a für die schon erwähnten Ergebnisse von $|11|$.

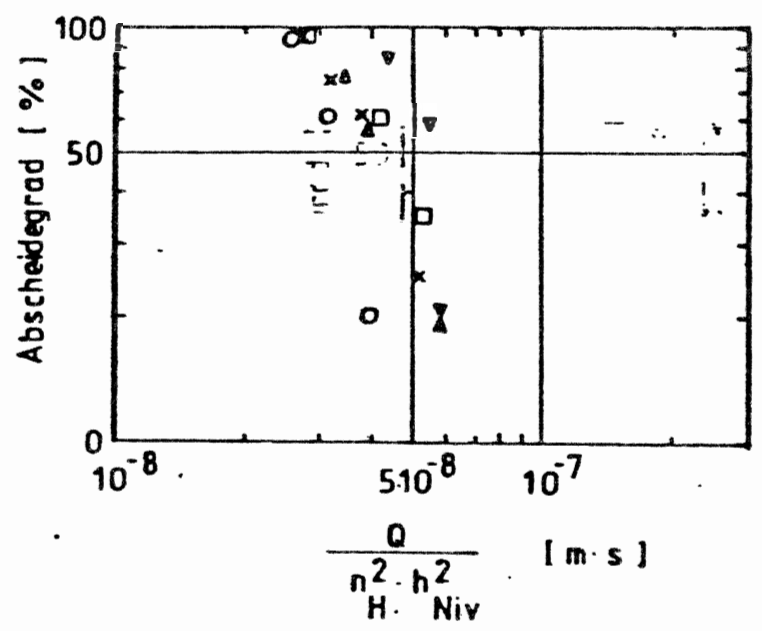

$\begin{array}{ccc} & h_{\mathrm{Niv}} & n_{H} \\ & 8,1 \mathrm{~mm} & 4000 \mathrm{~V} / \mathrm{min} \\ 0_{1} & 8,1 \mathrm{~mm} & 5000 \mathrm{~V} / \mathrm{min} \\ \times \quad 8,1 \mathrm{~mm} & 6000 \mathrm{~V} / \mathrm{min} \\ \Delta \quad 11,1 \mathrm{~mm} & 4000 \mathrm{Vmin} \\ 0 \quad 16,1 \mathrm{~mm} & 4000 \mathrm{~V} / \mathrm{min}\end{array}$

Abb. 13a. Darstellung der Versuchsergebnisse von von Kannenberg über den Parameter $\frac{\mathrm{Q}}{\mathrm{h}_{\mathrm{Niv}}^{2} \cdot \mathrm{n}_{\mathrm{H}}^{2}}$ 
Wenr man bedenkt, dab mit der veränderten Hapt-drehzahl wegen der konstanten Getriebelinersetzung sich auch die Differenzdrehzahi im Verhältnis von 1:1,15 geändert hat und daß durch die Niveauänderung im Bereich 1 - 2 gleichzeitig das Strömungsprofil leicht verändert wird (Haftbedingung nicht nur am Boden sondern auch an den Schneckenflanken), so ist die vorhandene Abweichung immer noch als sehr gexing anzusehen.

Die analoge Auftragung nach der Theorie der äquivalenten KIärfläche würde, wie Abb. 13b zeigt, keine Ubereinstimmung bringen.

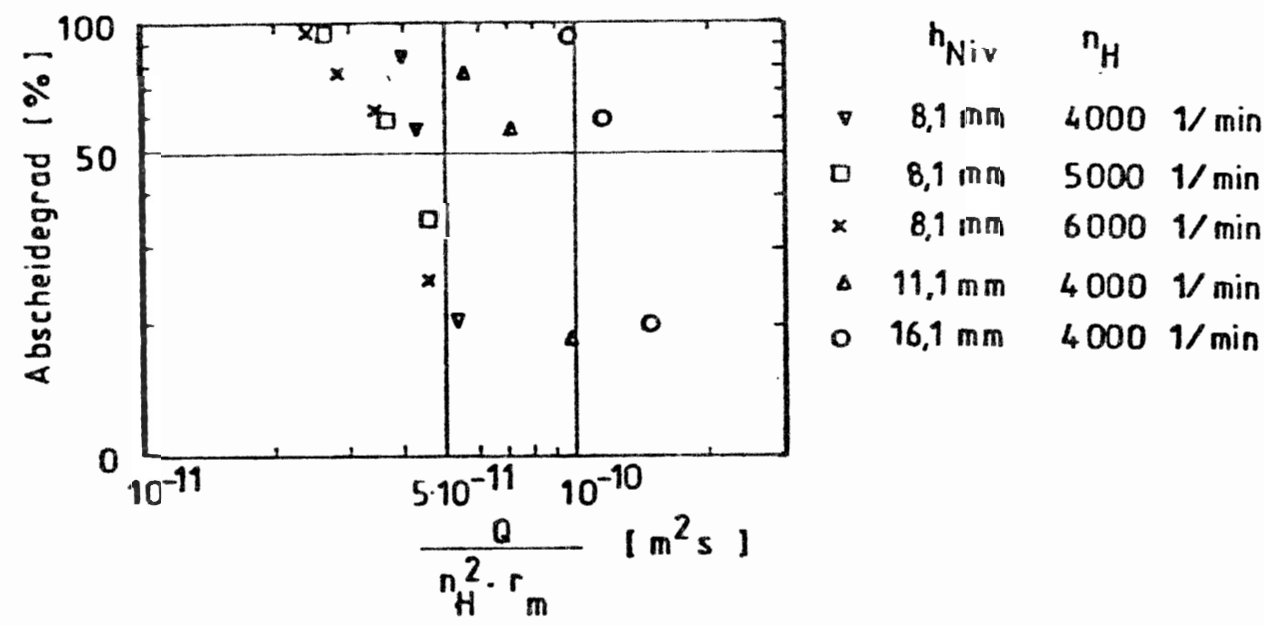

Abb. 13b. Darstellung der Versuche von Kannenberg über den Parameter $\frac{Q}{n_{H}^{2} \cdot r_{m}}$ 
Ein anderes Exgebnis mit einer Betriebsmaschine von uber 600 m Durchmessex, betrieben mit einer geflockten suspension eines sehr feinen mineralischen Schlamms, zeigt iber einet crveiterten Kennziffer aufgetragen, für die angegebenen Variationen von C-Wert, Niveauhöhe und der hier aus betrieblichen Gründen sich ändernden Zähigkeit der Flüssigkeit recht brauchbare Ergebnisse für die Bedingungen eines während der Produktion durchgeführten Feldversuchs (Abb. 14).

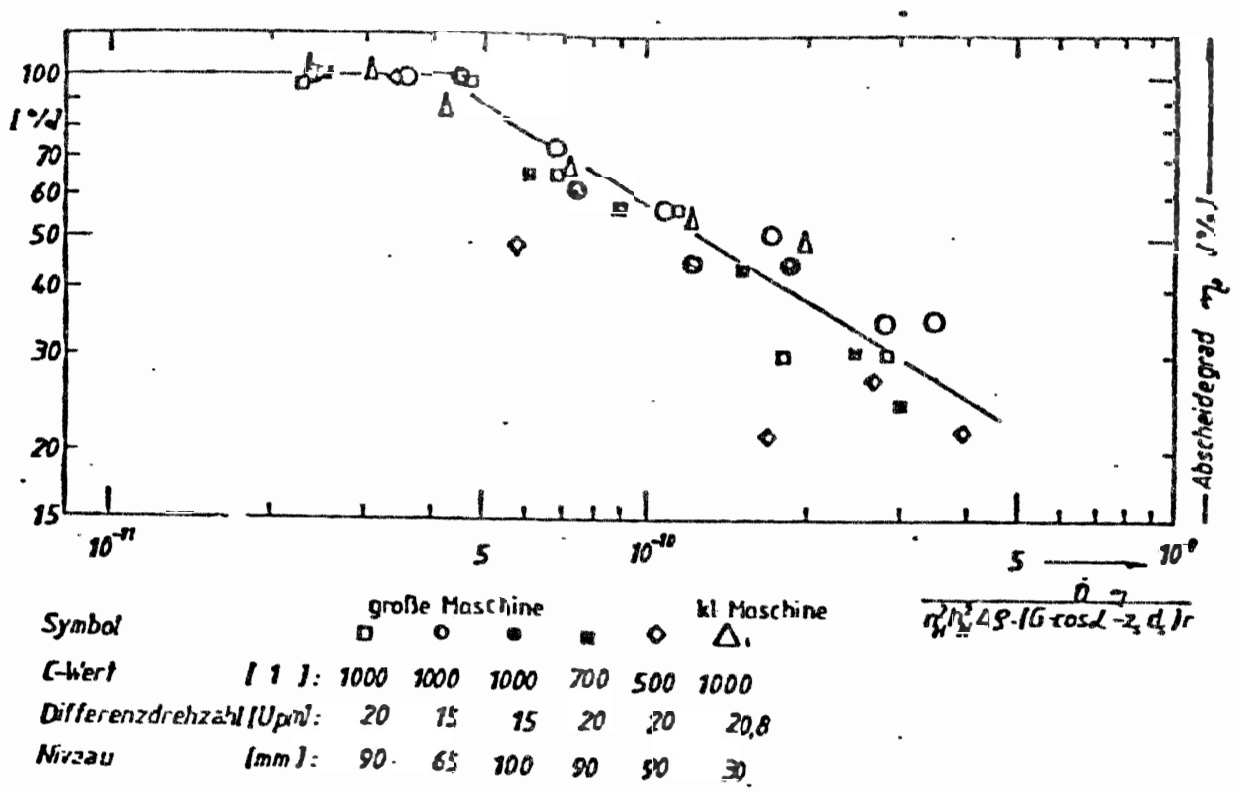

Abb. 14. Der Abscheidegrad als Funktion von $\frac{Q \cdot n}{r_{m} \cdot n_{H}^{2} \cdot h_{N i v}^{2} \cdot \Delta \rho \cdot\left(G \cdot \cos \alpha-z_{s} d_{s}\right)}$ für eine mineralische suspension

Man beachte, daB in diesem Diagramm ebenfalls die vorher durchgeführten Pilotversuche mit einem kleinen Dekanter dargestellt sind. 
Obwohl die Beziehung zwischen Schergefälle und zentratdurchsatz nur für den laminaren Fall hergeleitet wurde, hat sich bisher diese quadratische Abhängigkeit von der Niveauhöhe auch bei Kanal-Reynoldszahlen bis über 15 ooo gezeigt. Die Niveauhöhen wurden dabei von $h_{N i v}=0,08 . r_{T}$ bis zu $0,31 . r_{T}$ variiert.

Der EinfluB der Strömungsform im Schneckenkanal bedarf einer Uberpfüfung durch die vorgesehenen Forschungsarbeiten. Es ișt zu erwarten, daB der Exponent mit steigenden Reynoldszahlen kleiner als zwei wird (EinfluB der Turbulenz).

Es läBt sich also als vorläufiges Ergebnis sagen, daB zur Beurteilung verschiedener Maschineneinstellungen eines Dekanters der Knickpunkt des Abscheidegrades die Kennzahl

$\frac{Q_{k r i t} \cdot n}{n_{H}^{2} \cdot h_{N i v}^{2} \cdot\left(G \cdot \cos \alpha-z_{s} d_{s}\right) \Delta \rho \cdot r}=K_{s}$

geeignet ist.

6. Versuch der Vorhersage des Abscheidegrads . für Bereiche $Q>Q_{\text {krit }}$

Obwohl nur in wenigen technischen Aswendungs-. fällen ein Abscheidegrad kleiner als $100 \%$ toleriert werden kann und deshalb der Verlauf der Kurve für den Praktiker von viel geringerer Bedeutung als die Kenntnis der Lage des Knickpunkts ist, soll dieser doch kurz angedeutet werden.

Mit steigendem Durchsatz verschiebt $\mathbf{s i c h} \mathbf{x}_{\mathbf{s}}$ in der Kornverteilung ins Gebiet gröBerer Partikelaurchmesser und je nach Verlauf der Verteilungs- 

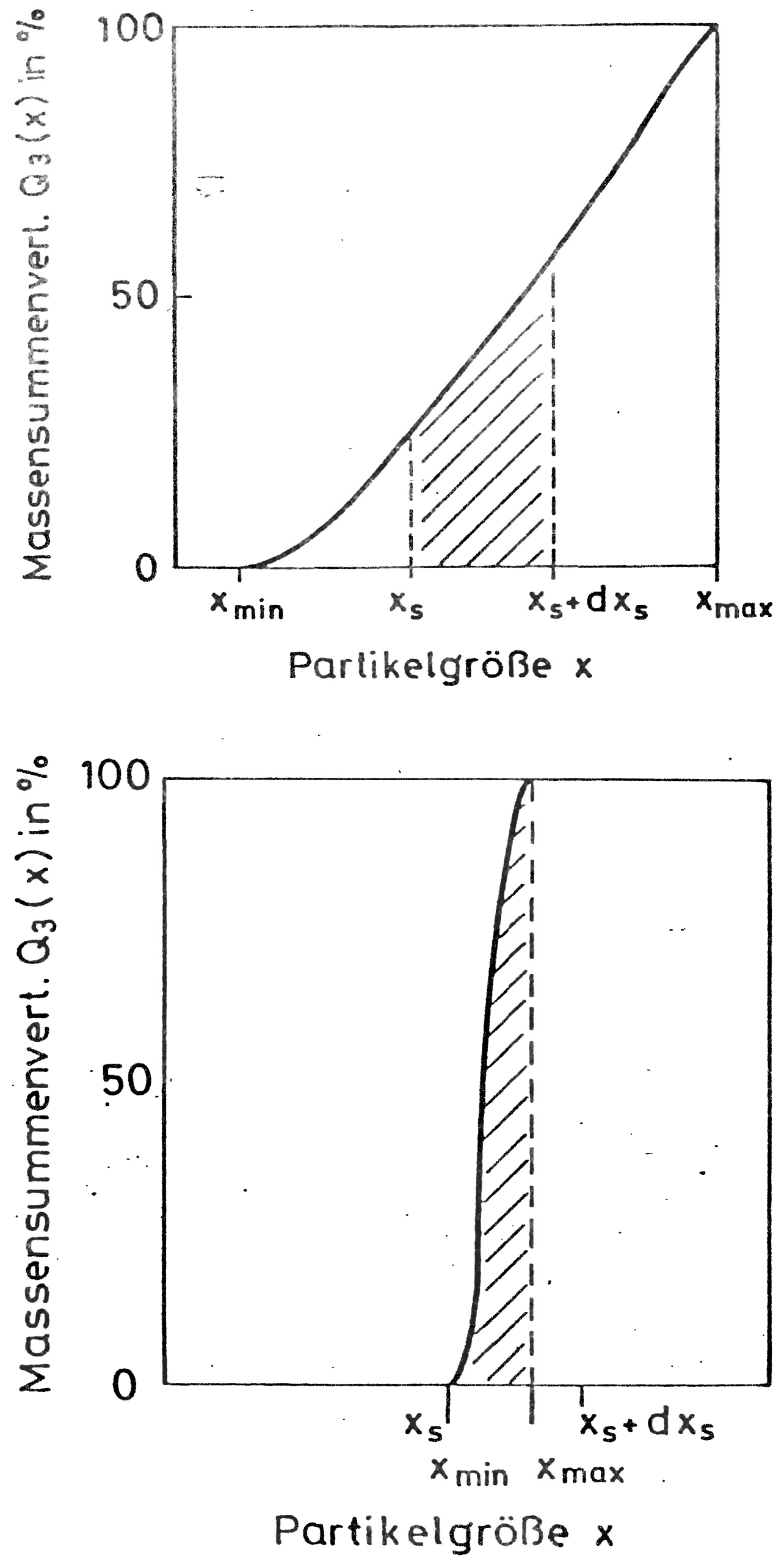

Abb. 15. Auswirkungen der Verschiebung des Schleppkornăurchmessers bei- verschiedenen Par-- 
kurve (siehe Abb. 15), wird man dabei eine

schnellere odex langsamere zunahme des Feststoffgehalts im Zentrat beobachten. Im Grenzfall absoluten Gleichkorns wäre zu exwarten, daB beim Schnitt von $x_{s}$ mit $x_{\text {prod }}$ die Klärung schlagartig zusamnenbricht, d.h. der Abscheidegrad vom kritischen Durchsatz ab senkrecht abfällt.

Dieses Klassierverhalten tritt bei technischen Suspensionen natürlich nicht so scharf auf; vor allem bei höheren Feststoffkonzentrationen wird Feingut mit dem gröberen Korn zusammen absinken und in den sedimentierten Kuchen eingelagert.

Trotzdem kann diese Berechnungsweise als Näherung verwendet werden, wie die Ergebnisse der Abb. 16 zeigen, die aus Messungen von Kannenberg $|11|$ stammen.

Kannenberg stellte schon 1962 fest, daB die gemessenen Abscheidekurven mit den nach der Stokesschen Theorie zu erwartenden Kurven weder in den absoluten Werten, noch in der Tendenz zusammenfallen.

Rechnet man die Ergebnisse nach dem Schleppkraftansatz durch, wobei man bei der verwendeten schmalen Fraktion für den Knickpunkt $x_{\min }=\mathbf{x}_{\mathbf{s}}$ setzt, so beschreiben die Rechenwerte den verlauf sehr exakt (Abb. 16). 


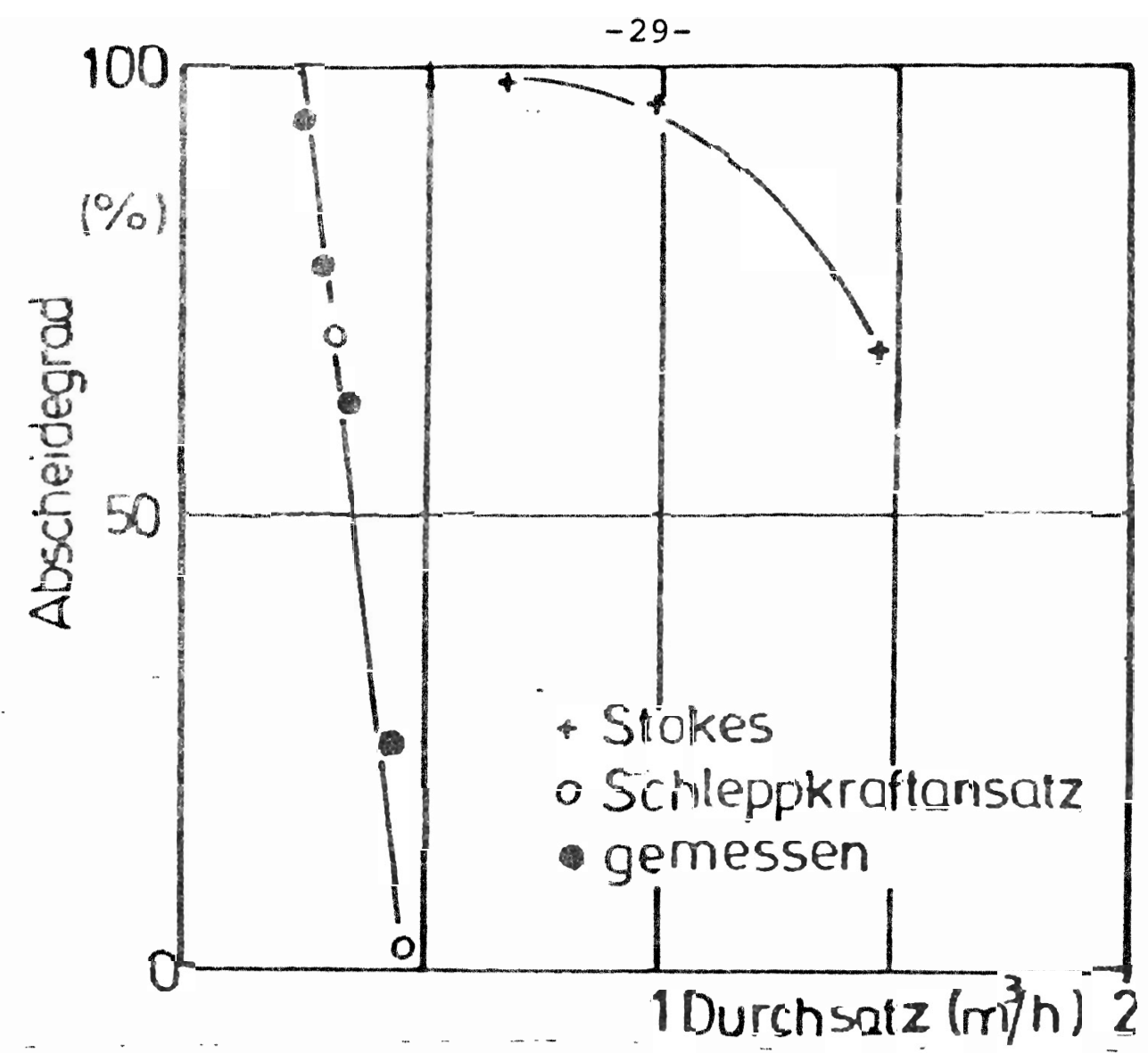

Abb. 16a. Der Abscheidegrad als Funktion des Durchsatzes $\mathrm{n}_{\mathrm{H}}=60001 / \mathrm{min}$, $\mathrm{h}_{\mathrm{Niv}}=8,1 \mathrm{~mm}$

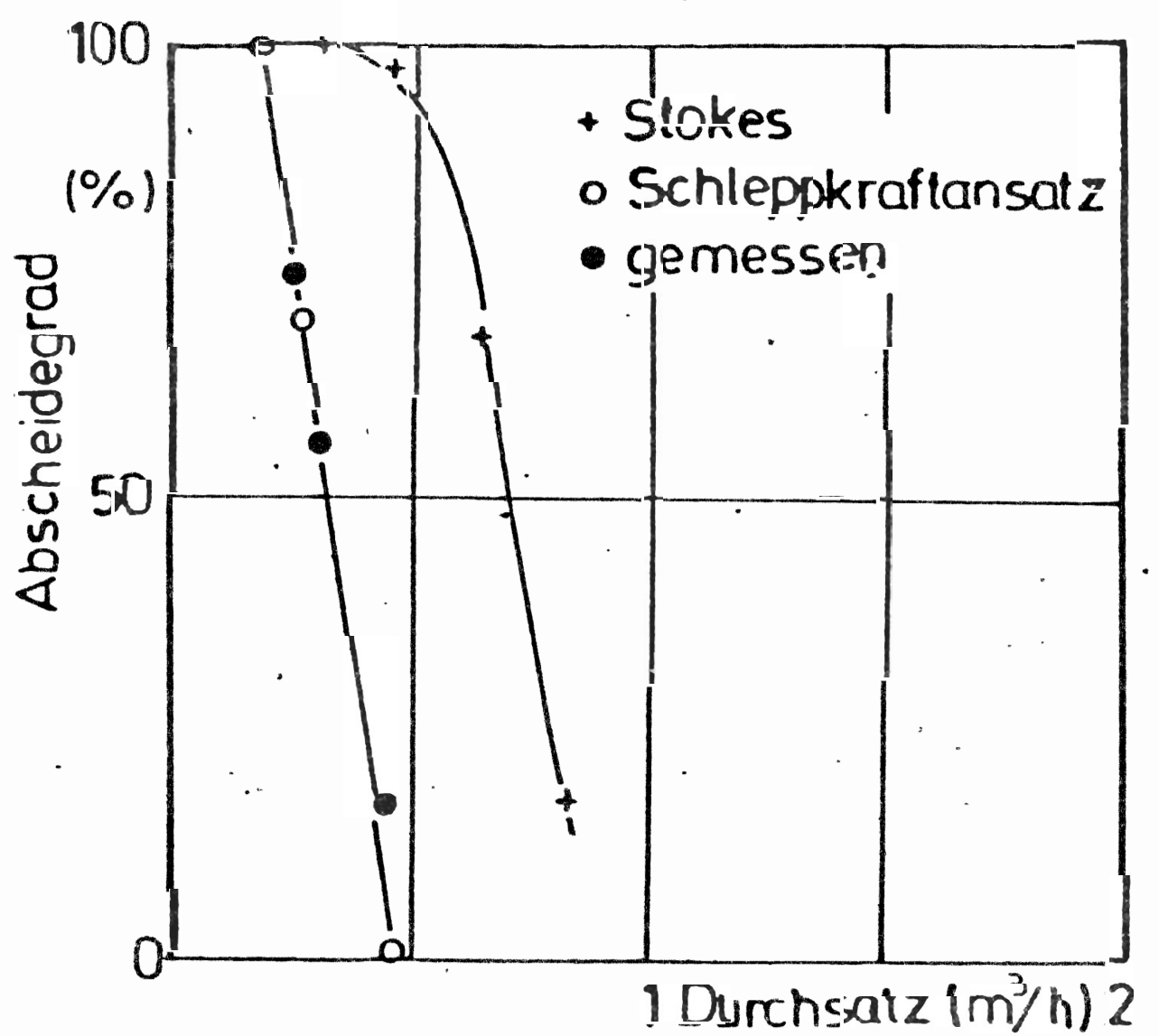

Abb. 16b. Der Abscheidegrad als Funktion des Durchsatzes $-\mathrm{n}_{\mathrm{H}}=-4000 \mathrm{i} / \mathrm{min}$. $h_{\text {Niv }}=11,1 \mathrm{~mm}$ 
7. Scale-up Methoden bei Bexückichtigung aer schjeppwirkung

Bel aer gegerwärtigen Unkenntnis des Schleppreibwertes fur verschiedene Produkte und Maschinenbedingungen ist es unumgänglich aen Knickpunkt in einem Pilotversuch zu finden und die Lage des Knickpunktes auf Maschinen anderer GröBen, Geometrien und Betriebseinstellungen zu ifbertragen. Dies hat aber auch den Vorteil, daß dex auftretende Schleppeffekt unter Maschinenbedingungen global gemessen wird und auf Annahmen oder ungenaue Labormessungen des wertes $f$ und den damit denkbaren ubertragungsfehlern verzichtet werden kann.

Der oben abgeleitete Ausdruck für den kxitischen Durchsatz läßt sich unter zusammenziehen der beim Scale-up ja unverändertenproduktdaten schreiben als

$$
\mathrm{Q}_{\text {krit }}=\text { konst } \cdot \begin{aligned}
& \mathrm{C} \cdot \mathrm{T} \\
& \mathrm{s}=\begin{array}{l}
\text { äquivalente Trak- } \\
\text { tionszahl }
\end{array}
\end{aligned}
$$

wobe 1

$$
c=\frac{r \omega^{2}}{g}
$$

$T=h_{N i v}^{2} \cdot\left(G \cdot \cos \alpha-z_{s} d_{s}\right)^{\prime}=$ Traktionszahl; sie fast alle konstruktiven

werte zusammen

Das Produkt aus beiden soll die äquivalente Traktionszahl genannt werden.

Verarbeitet man eine suspension in zwei verschieden großen Dekantierzentrifugen bei gleichen Beschleunigungen, so exgibt sich bei der un den 


$$
\begin{aligned}
& Q_{\text {krit }}=w_{s t} \cdot C \cdot A \\
& \Sigma=\text { äquivalente KIär- } \\
& \text { fläche }
\end{aligned}
$$

Neben diesen - wie eingangs erwähnt - bisher ausschließlich verwendeten Kennwerten A bzw. $\Sigma$ für einen Dekanter wird man nun unabhängig davon auch noch die analogen Kenngrößen $T$ und $S$ benutzen müssen, um der Kapazitätsbegrenzung durch das Wegschleppen von Teilchen gerecht $z u$ werden.

Je größer der Wert $T$ eines Dekanters, desto mehr kann der Durchsatz erhöht werden, ohne daB MitreiBen der Teilchen eintritt.

Abb. 17 zeigt die Daten einiger von verschiedenen Herstellern gebauter Dekanter unterschiedlicher Größe. Die maximale Niveauhöhe wurde mangels genauer Dateneinheitlich für alle Maschinen so festgelegt, daB zwischen maximaler Niveauhöhe

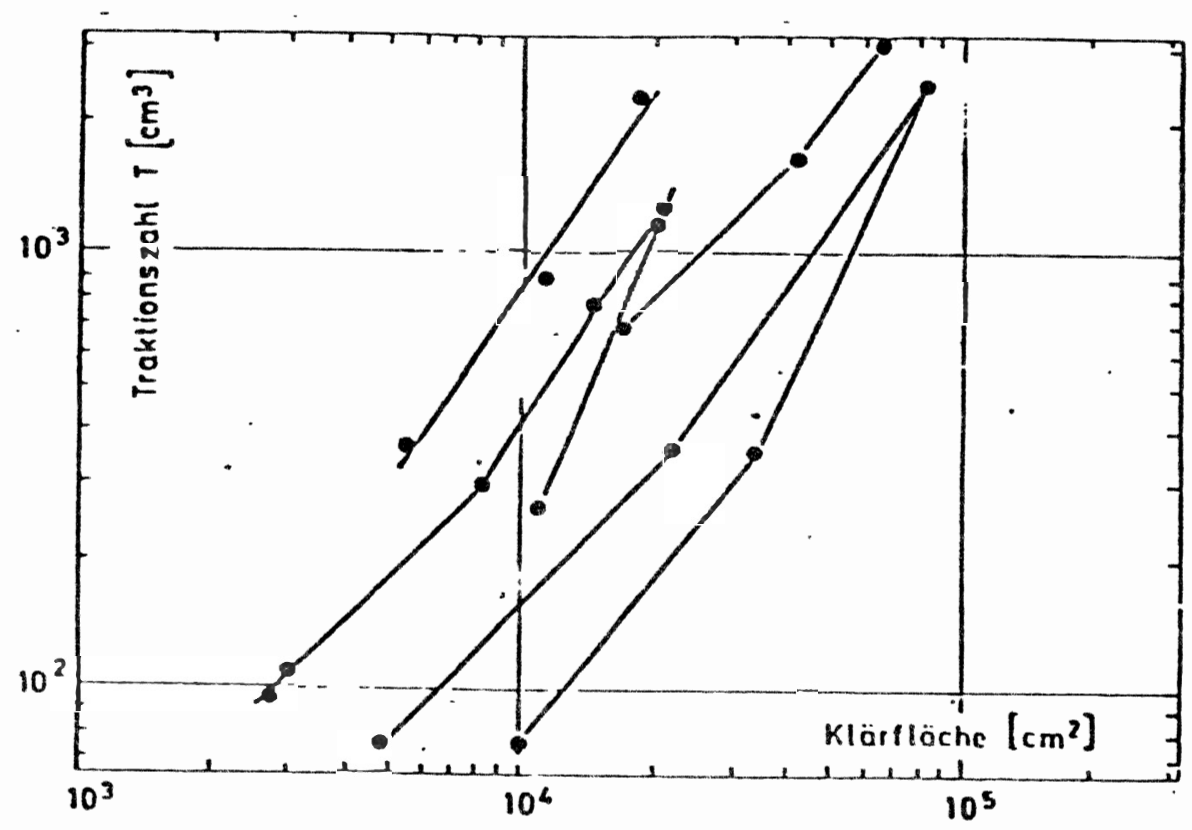

Abb. 17. Die Traktionszahl als Funktion der Klärfläche für verschiedene Dekanter 
und dem Feststoffaustragsrajus eine Differenz von 10 des zylindrischen Tromelradius vorhanden ist. Verschieden grobe Maschinen derselben Hersteller sind mit einer Geraden verbunden.

Fir verschieden große Maschinen absolut thnlicher Geometrie, wie sie z.B. in Abb. 18 mit zwei fiktiven Baureihen der Normreihe $\mathrm{R} 10$, d.h. mit einem stufensprung benachbarter GröBen von $i=1,25$ durchgerechnet wurde, erhält man im doppeltlogarithmischen Masstab eine Gerade der Steigung 1,5, da die ordinate mit der 3. Potenz, die Abszisse mit der 2. Potenz des stufensprungs wächst.

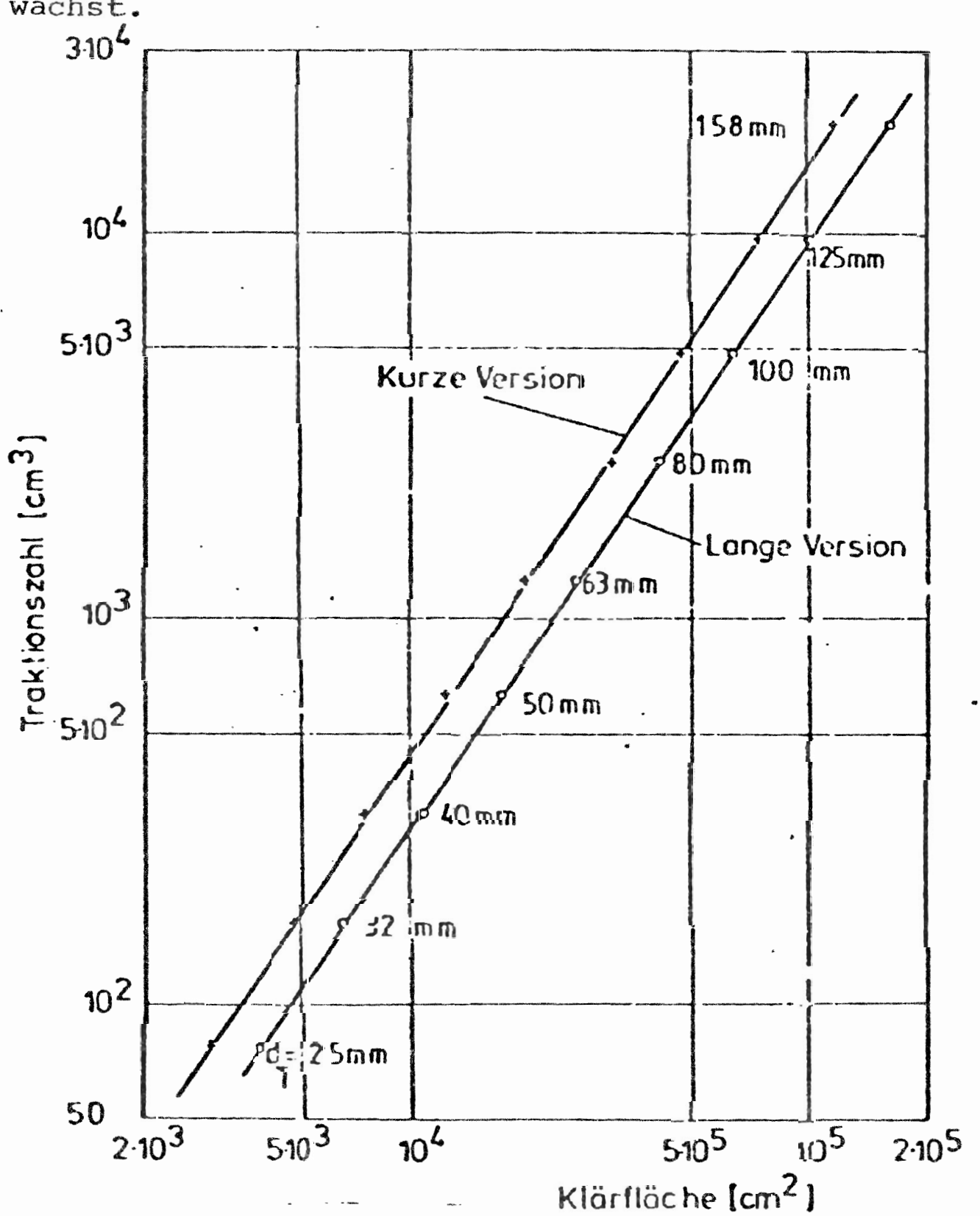

Abb. 18. Die. Traktionszahł ais Funktion der KIärfläche für die angenommene Dekanterbaureihe. 
In Anherg sind in Tabelle 1 für zwei fiktive Baureihen, die sich untereinander nur Jurch die Klärlänge unterscheiden, die Traktionszahl, die äquivalente Traktionszahl, die Klärfläche und die äquivalente Klärfläche aufgelistet.

Dabei wurden folgende realistische Annahmen getroffen:

$$
\begin{array}{ll}
h_{\text {Niv,max }} & =0,15 \cdot d_{T} \\
G & =0,25 \cdot d_{T} \\
d_{S} & =0,015 \cdot d_{T} \\
L_{Z Y I} & =1,5 \mathrm{bzw} \cdot 2,0 d_{T}
\end{array}
$$

Wegen der geometrischen Ähnlichkeit ist der Schneckensteigungswinkel $\left(\operatorname{tg} \alpha=\frac{G}{2 \cdot \pi \cdot r_{T}}=0,0796\right)$ mit $\alpha=4,55$ grad für alle Größen konstant; dex $\cos \alpha$ wird deshalb näherungsweise gleich 1 gesetzt.

In Abb. 19 sind dieselben ausgeführten Maschinen und in $\mathrm{Abb}$. 20 die beiden fiktiven Maschinenbaureihen eingezeichnet.

Wie erwähnt, sinkt bei gröBer werdendem Durchmesser wegen der Materialfestigkeit der c-Wert; dies wirkt sich.in dieser Darstellung so aus, daB die Abszisse linear, die ordinate quadratisch mit dem Stufensprung zunimmt.

Eine Änderung der Umfangsgeschwindigkeit eines Dekanters bewirkt in $\mathrm{Abb}$. 20 eine Verschiebung des Betriebspunktes mit der steigung 1. Für die Hochrechnung vom Pilotversuch, bei dem natürlich die stelle des kritischen Durchsatzes eindeutig lokalisierbar sein muB, wird der für die anvisierte Maschine mögliche Grenzdurchsatz ge- 


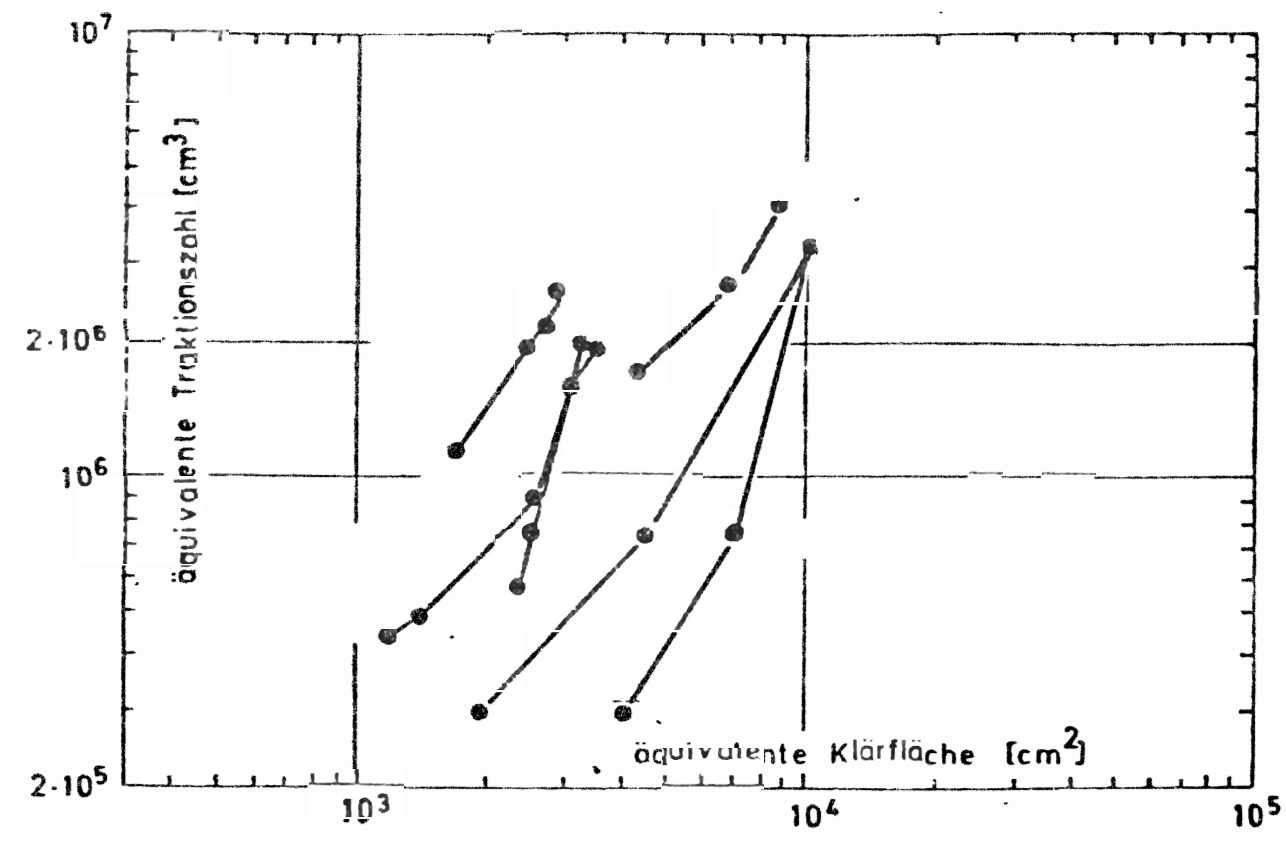

Abb. 19. Die äquivalente Traktionszahl als Funktion der äquivalenten Klärfläche für verschiedene Dekanter

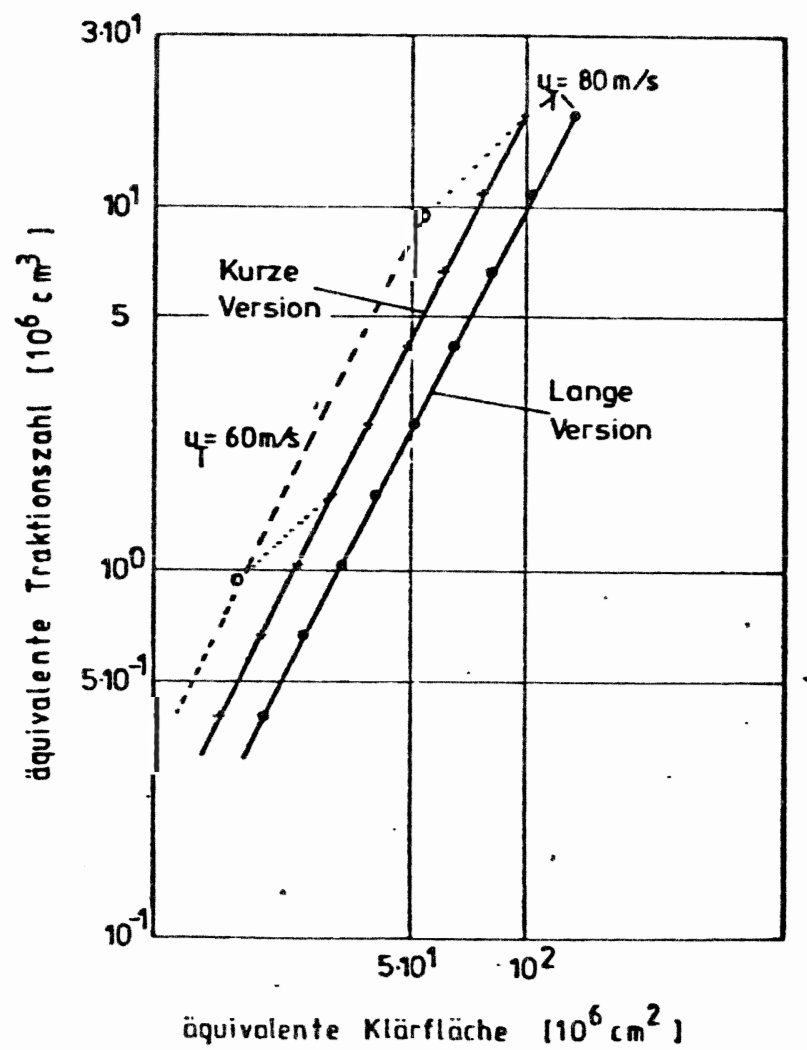

Abb. 20. Die äquivalente Traktionszahl als Funktion der äquivalenten Klärfläche für die angenommene Dekanterbaureihe 
Eunden und entschieden, ob die gewünschte Kapazitat durchgesetzt werden kann oder es wird umgekehri aus dem geforderten Durchsatz eine verfugbare MaschimengröBe ausgewählt, deren kitischer Durchsatz hoher liegen würde als die geforderte Kapazitä.

Es empliehlt sich dabei die Versuche mit dem Pilotaekantor schon mit dern $\mathrm{C}$-Wert des anvisierten Grobdekanters anzusetzen, um evtl. vorhandene von der Beschleunigung abhängige Produkteinflüsse auszuschalten.

Damit ist zunächst nur die Sicherheit gewonnen worden, daB der Klärvorgang auf der groben Maschine ohne störende Schleppwirkung abläuft; wie groB allerdings dabei der Feststoffgehalt im Zentrat sein wird, kann aus dem auf der Pilotmaschine gefahrenen Betriebsbereich nicht unmittelbar übertragen werden.

Die um n.i gröBere Maschine hat bei gleichem $c$-Wert einen um $(n . i)^{3}$ gröBeren kritischen Durchsatz; die Klärflächenbelastung $\frac{Q}{A}$ (beim selben C-Wert) steigt aber deshalb beim groBen Dekanter auf höhere werte an.

Dieser Bereich höherer Klärflächenbelastung - ohne in die Schleppwirkung hineinzukommen ist im Modelldekanter nicht fahrbar; es können deshalb auf experimenteller Basis keine Aussagen über den weiteren Verlauf des Feststoffdurchschlags über den Punkt 1 hinaus erhalten wexden (Abb. 21a).

Wenn man den weiteren Verlauf nicht nur durch Extrapolation festlegen will, so muB man hier auf eine Abschätzung zurückgreifen, die auf dem stokesschen Gesetz basiert. 

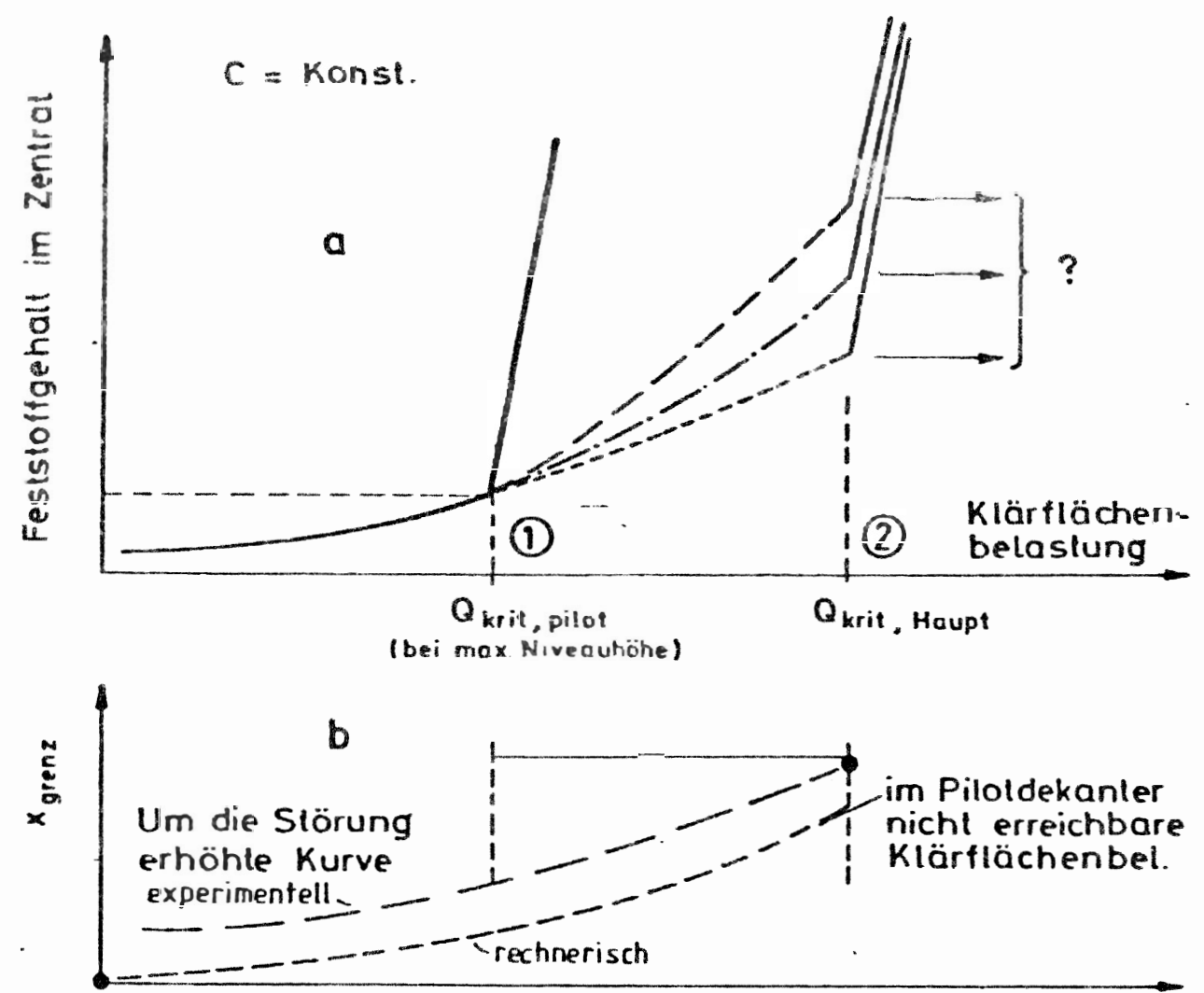

Klärflächen-

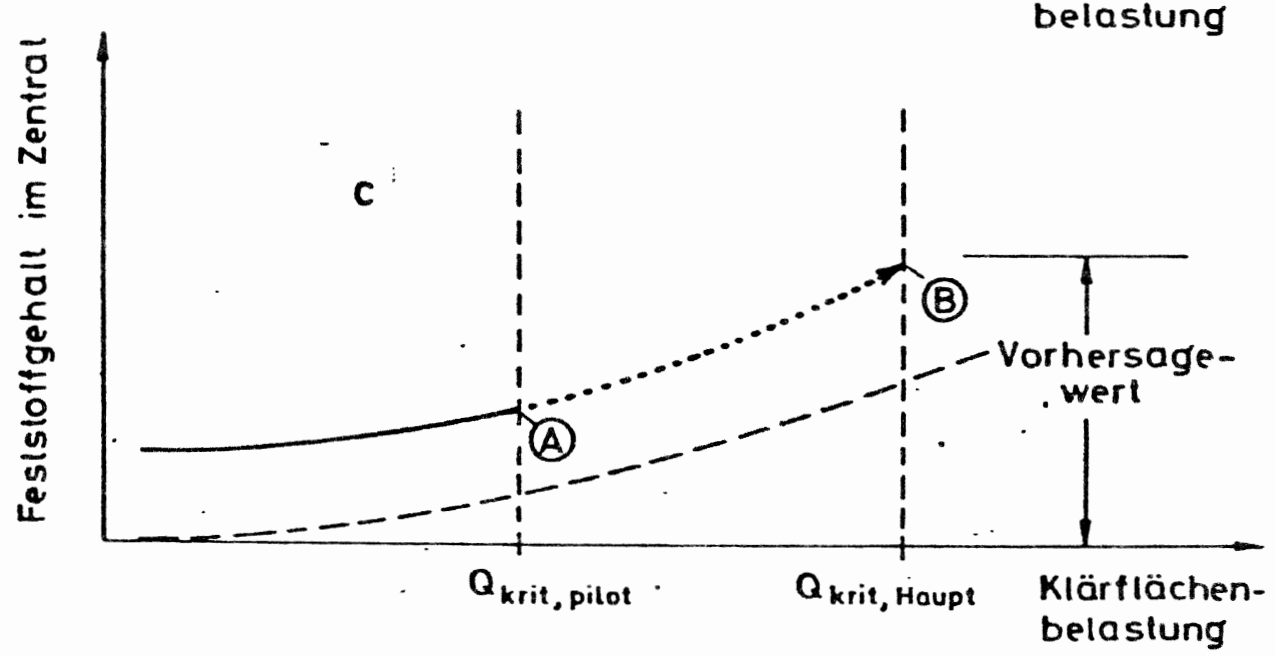

Abb. 21. Zur Hochrechnung von Pilotversuchen 
Man erxechnet sich die Grenzkorngröße als Funktion ber KIärflächenbelastung und trägt diese Wertepare ibereinander auf (Abb. 21b). GemäB dem in Kap...6 beschriebenen veriahren errechnet man araus ibex die Kornvertelinngskurve den Feststoffurchschlag im zentrat.

Er wird ebenfalls iber der KIärflächenbelastung aufgetragen (Abb. 21c). Die Kurve liegt sicher tiefer als die gemessene. sie kann aber jetzt. rein rechnerisch bis zum wert ( $\left.\frac{\text { krit, Haupt }}{A}\right)$ bestimmt werden.

Anhand dieser Leitlinie fällt nun die doch noch durchzufühende Extrapolation der experimentellen werte von $A$ zu B etwas weniger gewagt aus als ohne dieses theoretische Hilfsmittel

$(\mathrm{Abb}, 21 \mathrm{c})$.

Basierend auf einigen Exfahrungen kann man die Empfehlung aussprechen, daB die gleiche störwirkung der Schneckendifferenzbewegung auf die Klärung etwa bei gleicher Differenzumfangsgeschwindigkeit, nicht bei gleicher Differenzdrehzahl zwischen Maschinen verschiedener Größe erreicht wird.

Aus diesem Grund ist es empfehlenswert, die Pilotversuche mit einer um den später gewählten Vergrößerungsmaßstab höheren Differenzdrehzahl anzusetzen.

In jedem Fall muB natülich sichergestellt sein, daB die Differenzdrehzahl wenigstens so hoch ist, daB in der Maschine kein Feststoffxückstau entsteht. 
8. Auswirkung der Schleppwirkung auf die Investitionskosten füx Klärdekanter

Die vorliegenden Erkenntnisse, nämlich daB die Klärwirkung in Dekantierzentrifugen meist von der Schleppwirkung begrenzt wird, und die dargelegte Quantifizierung, lassen jetzt auch eine Wirtschaftlichkeitsbetrachtung der Investitionskosten für Dekanter zu. Die Preise verschieden groBer aber ähnlicher Dekanter einer Baureihe lassen sichin einer doppelt-logarithmischen Auftragung näherungsweise durch die Funktion $\log P=\log P_{0}+m \cdot \log \left(d-d_{0}\right)$

beschreiben (siehe $\mathrm{Abb}, 22$ ). Po ist dabei der Preis eines aus der Serie beliebig gewählten Dekanters des zylinderdurchmessers $d_{0}$. Der Gradient $m$ wird je nach Baureihe individuell verschieden sein und hat auf den grundsätżlichen Verlauf des Folgenden keinen EinfluB.

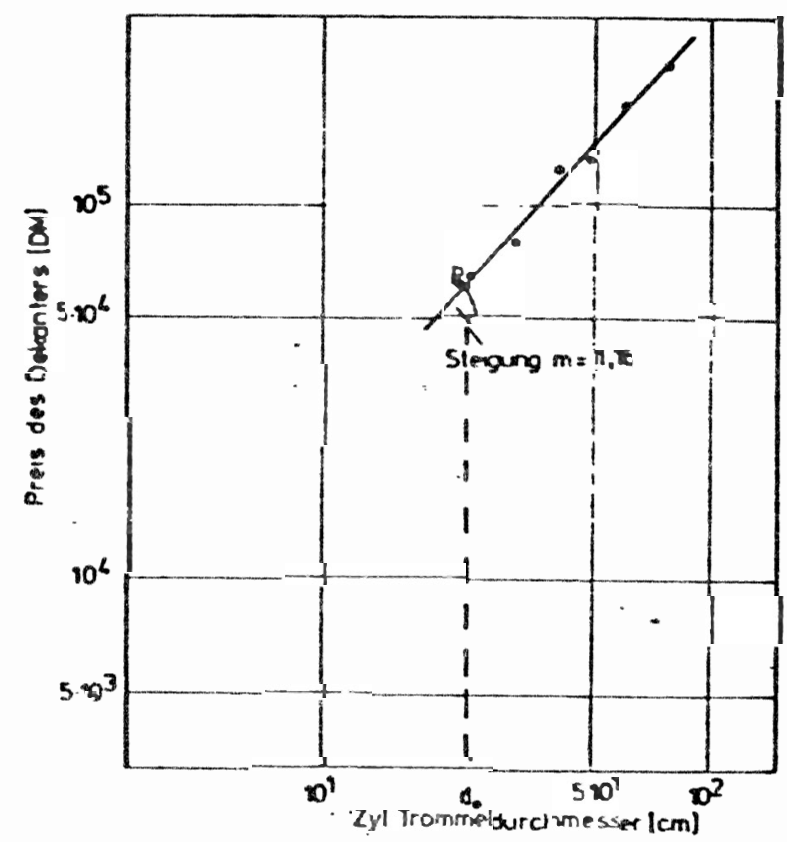

Abb. 22. Der Kostenverlauf für eine Dekanterbaureihe 
Es wixd angenommen, daB aus Verfahrensgründen Igleiche erzielbare Restfeuchte, gleicher spez. Flockungsmittelbedarf, usw.) alle Dekanter mit gleichen zentrifugalbeschleunigungen gefahren werden.

Berechnet man nun jewells zusammengehörige werte von $\mathrm{I}$ und $\mathrm{F}$, so ergibt sich mit dem beliebig gewahlten startpunkt des kleinsten Dekanters $\left(P_{0}=\right.$ Einheitswert) der oben festgelegten fiktiven Dekanterserie $A$ bis I und drei frei gewählten steigungswerten von $m=1,15$ und $m=1,3$ und $m=1,5$ die folgende rabelle 2 .

\begin{tabular}{|c|c|c|c|c|c|c|c|c|c|}
\hline Typ & $A$ & B & $c$ & D & $E$ & $F$ & G & $\mathbf{H}$ & I \\
\hline$d_{T}$ & 25 & 32 & 40 & 50 & 63 & 80 & 100 & 125 & 158 \\
\hline $\mathbf{T}$ & 77,3 & 162,2 & 316,8 & 618,8 & 1237,7 & 2534 & 4950 & 9668 & 19524 \\
\hline$\frac{T_{i}}{T_{A}}$ & 1 & 2,098 & 4,098 & 8,00 & 16.01 & 32.78 & 64,03 & 125,07 & 252,57 \\
\hline $\begin{array}{l}P \\
m=1,15\end{array}$ & $1=P_{0}$ & 1,972 & 2,532 & 2,60 & 2,817 & 3,001 & 3,156 & 3,3 & 3.42 \\
\hline $\begin{array}{l}p \\
m=1,3\end{array}$ & $1=P_{0}$ & 2,1 & 2,53 & 2,817 & 3,054 & 3,262 & 3,438 & 3.6 & 3.74 \\
\hline $\begin{array}{l}\mathbf{p} \\
\mathrm{m}=1,5\end{array}$ & $1=P_{0}$ & 2,26 & 2,764 & 3,097 & 3,37 & 3,61 & 3,812 & 4 & 4,165 \\
\hline $\begin{array}{l}\frac{T_{i}}{T_{A}}: \frac{P_{i}}{P_{0}} \\
\text { be i } 1,5\end{array}$ & 1 & $\begin{array}{l}1,064 \\
\end{array}$ & 1,742 & 3,077 & $5,683$. & 10,92 & 20,28 & $\begin{array}{r}37.9 \\
: \\
\end{array}$ & 73,85 \\
\hline bed 1,3 & 1 & 1,0 & 1,62 & 2,84 & 3.242 & 10,05 & 18,624 & 34.74 & 67.53 \\
\hline bei 1,5 & 1 & 0.928 & 1,483 & 2,58 & 4,751 & .9 .08 & 16,8 & 31,26 & 66,71 \\
\hline
\end{tabular}


Bildet man dann das Verhältnis maximaler Durchsatz pro Preis einer beliebigen Maschine zu maximalem Durchsatz pro Preis der kleinen Maschine und trägt es über den Trommelradius auf, so sieht man, dab in allen drei untexschiedluchen preisprogressionen der kennwert für die "Preiswardigkeit" sehr steil ansteigt (ABb. 23).

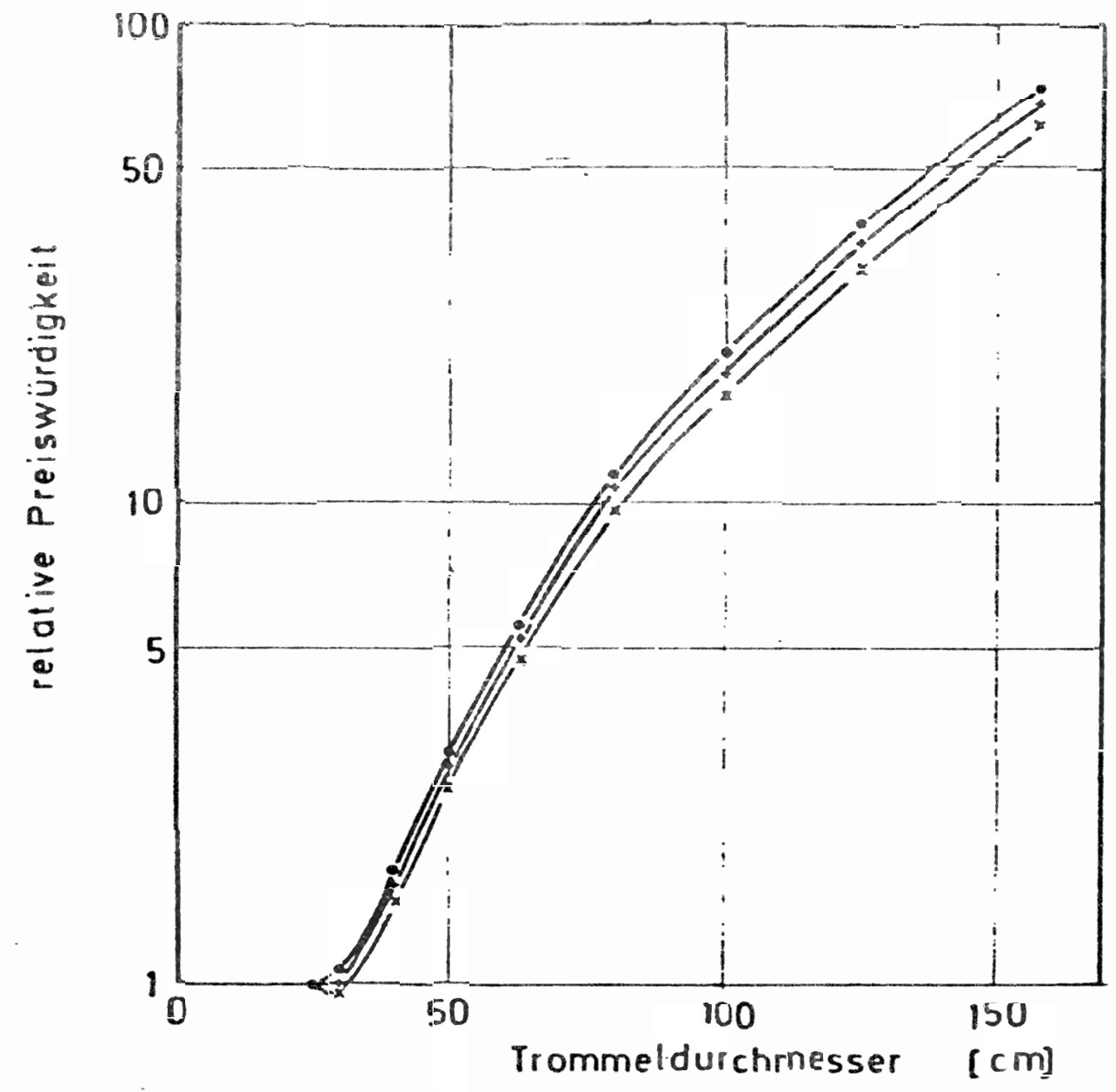

$\mathrm{Abb} .23$. Die relative Preiswirdigkeit verschieden großer Klärdekanter

Daraus läBt sich ableiten, daB - von der seite der Investitionskosten betrachtet - eine Aufsplittung der. Produktionsrate in zwei oder mehrere Maschinen absolut unwirtschaftlich ist, es sollte jeweils die Gesamtkapazität von einer einzigen großen Maschine verarbeitet werden.

Andererseits zeigen die oben behandelten "Theorien, daß die steigerungsmöglichkeiten durch 
Gangverbreiterurg, Niveaverhöhung und Klärflächenerweiterung bei kleinen und mittleren Maschinen basonders gros sind.

9. Maschinentechnische Folgerunger

9.1 Gleich- und Gegenstromaekanter

Die oben erwähnten Gesetzmäßigkeiten gelten zunächst nur für den Gegenstromdekanter, bei dem sich die feineren Teilchen auf eine durch die Schnecke überschliffene ebene und sehx glatte Grundschicht absetzen. Dex Gleichstromdekanter bietet den der Anströmung ausgesetzten Feinstteilchen einen besseren Schutz gegen Abspülen. Da beim Gleichstromaekanter der größte Teil des Feststoffs von der Aufgabezone am Ende des $\mathrm{zy}$ Iinders über die ganze zylinderlänge transportiert wird und dabei einen kuchen formt, der den Zylindermantel vorwiegend bedeckt, finden die später sedimentierenden Feinstteilchen in diesem Fall eine weniger glatte, eher hügelige Kuchenoberfläche vor, in deren Unebenheiten sie vor einem weiteren Abspülen geschützt sind. Dieser Vorgang dürte die Hauptursache für die bekannt gewordenen hohen Klärleistungen der Gleichstrommaschinen sein, wenn man bei einem echten Vergleich zum Gegenstromdekanter alle anderen Parameter konstant läßt.

\subsection{Niveauerhöhung}

Obwohl die Gleichung 14 ausweist, daB der Knickdurchsatz mit weiterer Niveauerhöhung gesteigert werden könnte, ergeben sich doch folgende Begrenzungen: 
- Der mittlere Beschleunigungswert nimmt mit steigender Niveauhöhe ab. damit vermindert sich die wirksamkeit der zentriruge.

- Entsprechend einex weitexen Niveuworhöhung mibte der Konus verlangert werden, um ders Schlamm uber das Niveau herauszuheben. Wegen der Probleme bei der Förderung dinn-pastösex Schlämme kann der Konuswinkel in allgemeinen nicht mehr erhöht werden. Dies führt aber zu einex längeren, teureren und im dynamischen Verhalten labileren Maschine.

- Obwohl versuche bis zu werten von $\frac{h_{N i v}}{r_{T}}=0,31$ die quadratische Abhöngigkeit gezeigt haben, ist dieses Gebiet sehr hoher Niveaueinstellungen noch nicht genügend abgesichert. Es wäre möglich, daB der Exponent von $h_{\text {Niv }}$ unter den Wert 2 abfällt.

Eine Erhöhung des Niveaus muB also im Zusammenwirken mit anderen Vorgängen gesehen werden und ist im Einzelfall sorgfältig abzustimmen.

\subsection{Erhöhung der Schneckensteigung}

Die VergröBerung der Schneckensteigung geht fast linear in die Durchsatzsteigerung ein. Jedoch sind auch bei dieser Anderung Nebenbedingungen zu beachten.

Im Bereich des Konus benötigt man besonders bei der Förderung von pastösen Schlämmen möglichst flache, enge Schneckengänge. Eine Erweiterung auf der Klärseite hat also ein konisches übergangsgebiet des Schneckenkanals zur Folge, in dem die im Bereich der Aufgabezone (Gegenstromdekanter) noch hohen strömungsgeschwindigkeiten kontinuierlich herabgesetzt werden. Dieser uber- 
gang der schnedkensteigung wrd sicher nur sanft exfolgen kcrnen, ura strömungsablosungen an den Kanalwänder zu vermeiden $|16|$.

9.4 Verandern des strömugsprofils im srmeckenkanal

Entsprechend dem Kxäiteansatz, siehe Abb. 8. kombt es darauf an, den Schergradienten am Boden herabzudrüken. Dies könte durch Einbauten entsprechend Bild 24 erreicht werden $|17|$.

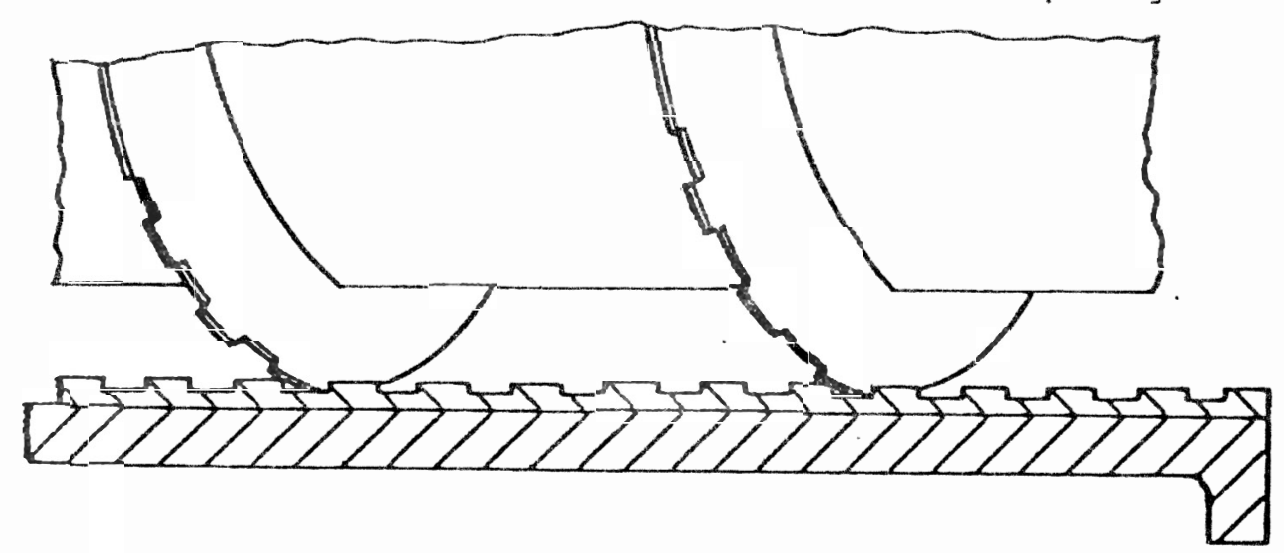

Abb. 24. Abstufungen in der Grundschicht eines Dekanters

\subsection{Abstoppen der mitgeschleppten Teilchen}

In einer Serie von Querrillen, Stokkanten o.ä. (Abb. 25), die nahe dem Trommelende angebracht wexden und die von der rotierenden schnecke in die Grundschicht bei jeder Umarehung nachgezogen werden, könnten mitgeschleppte Teilchen 


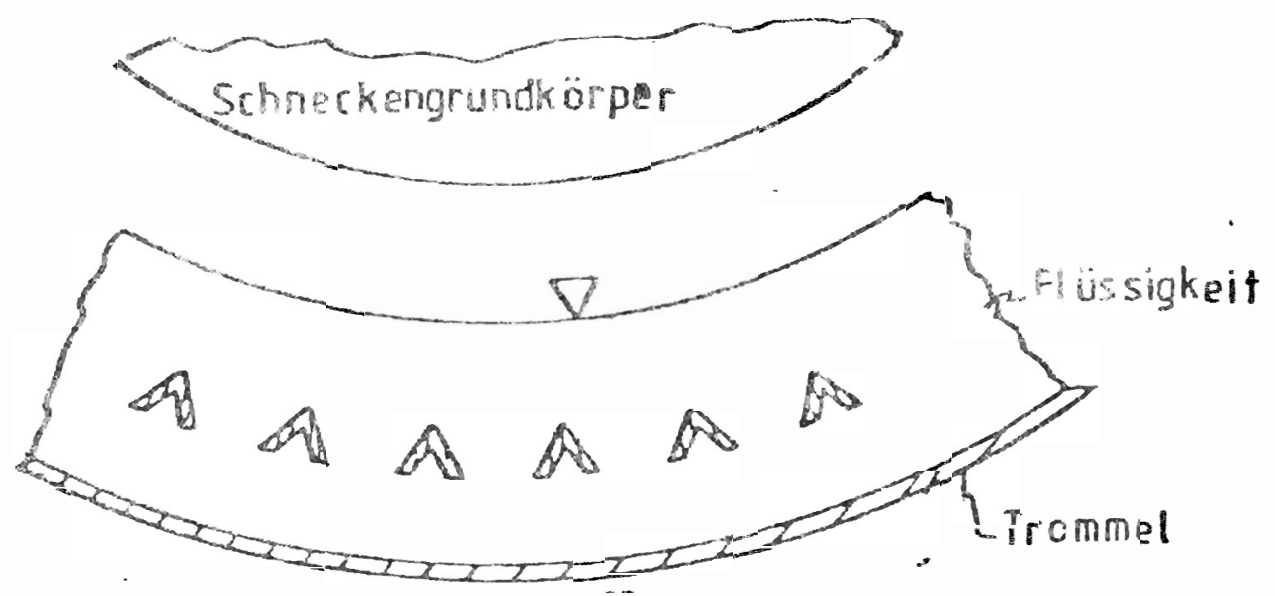

Abb. 25. Profilleisten

festgehalten und trotzdem - zu einem kleinen Kuchen vor dem Schneckenblatt zusammengeschabt ohne von der Strömung wieder'angegriffen $\mathrm{zu}$ werden zum Feststoffauswurf transportiert werden. Solche Konfigurationen wurden in einem Kanal im Erdfeld bereits getestet, und es wurde gegenüber einem glatten Grund eine erhebliche steigerung festgestellt.

9.6 Fỉhrung des Zentrats auBerhalb der Schneckenkanäle

Um die Stxömungsgeschwindigkeiten des Zentrats im Rotor herabzusetzen, ist schon von verschiedenen Autoren vorgeschlagen worden, der Flüssigkeit einen axialen weg vorzugeben und sie nicht in den Spiralkanal zu zwingen. Die konstruktiven Lösungen führen zu Bandschnecken, Einbauten mit axialen Führungskanälen und perforierten Schnecken- 
blattern. Obwohl viele solcher vorschläge auch aus der patentikeratur seit iangem bekannt wurden sind den futoren vergleichende Untersuchungen nicht bekantgewoxän. Diese Lösungen haben sich auch nicht in dex pras verheitet.

\section{SchiuBwort}

Um verläBliche Aussagen zu exarbeiten, müssen Dekanter sehr untexschiedlicher GröBe in Laborund Betriebsversuchen durchgemessen werder.

Diese Aufgabe haben wir uns am Institut in den nächsten Jahren zum ziel gesetzt. Wir hoffen dabei auf eine fachiche Resonanz aus der Indüstrie und auf das Verständnis der mit der Forschungsförderung betrauten personen una Insti-. tutionen.

\section{Anhang:}

\begin{tabular}{|c|c|c|c|c|c|c|c|c|c|c|c|c|c|c|}
\hline Iyp & $\begin{array}{l}\text { Durchmes } \\
\text { wer des } \\
2 y \text { l. } \\
\text { com }\end{array}$ & $\begin{array}{l}\begin{array}{c}\text { ns vesu- } \\
\text { hole } \\
\text { cas }\end{array}\end{array}$ & $\mid \begin{array}{c}\text { Gang- } \\
\text { hohe }\end{array}$ & $\mid$ & $\left|\begin{array}{c}\text { Dleref } \\
\text { dicke } \\
0\end{array}\right|$ & $\begin{array}{c}\text { rreke ions } \\
\text { sahd } \\
\mathrm{cas}^{3}\end{array}$ & \multicolumn{2}{|c|}{ 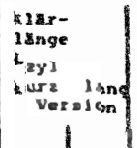 } & \multicolumn{2}{|c|}{ 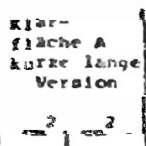 } & $\begin{array}{l}c \\
\operatorname{mex} \\
u= \\
000 / 8\end{array}$ & $\begin{array}{c}\sin \Rightarrow \operatorname{sepp-} \\
\sin 1 \\
5.10 \\
a^{3}\end{array}$ & \multicolumn{2}{|c|}{ 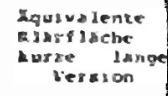 } \\
\hline ش & 23 & 3.75 & 6.25 & 2 & 0.370 & 27.3 & 37.5 & so & 2045 & 3จ์ว? & 5220 & 0.408 & 13.378 & 20.499 \\
\hline - & 32 & 4.8 & 8.0 & 2 & 0.48 & 162 & es & 6 & 4823 & 6436 & 4175 & $0.677 \times 4$ & 20.015 & 28.862 \\
\hline c & 10 & 6.0 & 10 & 2 & 10.6 & 386 & 60 & $\infty$ & 2340 & $1003:$ & 3262 & 1.033 & 24.595 & 32.793 \\
\hline D & so & 9.5 & 12.5 & 2 & 0.75 & 628 & 75 & 100 & 11288 & 15708 & 26.10 & 1.815 & 30.380 & 40.998 \\
\hline$\Sigma$ & 63 & 9.85 & 13.75 & 2 & 0.945 & pias & 94.3 & 123 & hasos & $2 a>s 0$ & 2078 & $x, 543$ & 38,346 & 51,237 \\
\hline$r$ & 10 & 22.0 & 20 & 2 & 8.2 & 2530 & 130 & 160 & poiss & 100212 & 8631 & 4.133 & 49. . 184 & C5. SE6 \\
\hline$\epsilon$ & 100 & 13.0 & 25 & 8 & 1.3 & los 50 & piso & $2 \infty$ & 37823 & prase & 1305 & 10.460 & 61.496 & 1.986 \\
\hline 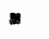 & 123 & 88.75 & $31.25^{\circ}$ & 2 & 1.875 & $\$ 668$. & 187.5 & 230 & 83628 & Se194 & 304 & $0.003=$ & 26.878 & 102.89 \\
\hline $\mathbf{x}$ & fise & 3.8 & 35.5 & 2 & 2.37 & 19526 & p34 & 3201 & 16121 & honasy & $\$ 70$ & P6.986 & 01.05 & 13e.19 \\
\hline
\end{tabular}




\section{Iiteraturveraeichnis}

11) Redecker, D. Chem。-lng.-Tech. 52 (1980) Nr. 52, S. 814/880

(2) Stahl, wo: Chem.-Ing.-Tech. 4t (1975) Nr.20, S. 853

|3| Smith, F.H., Hebb, M.H., in: Encyclopedia of Chemical Technology (Kirk, Otthmer). Bd. 3, S. 501-521, Interscience New York 1949

14| Ambler, Ch.M.: Chem.Eng.Prog. 48 (1952) Nr. 48, S. $151 / 158$

15) Ambler, Ch.M. = Ind.Eng.Chem. 53 (1961) Nr.6, S. $430 / 433$

|6| Trawinski,H., in: Encyclopädie der technischen Chemie. (Bartholomë, E., Biekert,E., Hellmann, H. Ley, H.) Bd. 2, S. 204/223, Verlag Chemie, Weinheim 1972

|7| Gösele, w.: Habilitationsschrift, Universität Stuttgart, 1971

181 Frampton, G.A.: Chem.Proc.Eng. (1963), S. $402 / 412$

|9| Mülier,H.,W., Schaffer,J.: Conrad, S.: Chem.Techn. 32.Jg., (1980) Nr. 2, S. $76 / 80$

$|10|$ Alt, C., Faust, T.: Strömungs- und Absetzvorgänge in Vollmantel-Schneckenzentrifugen, Arbeitsbericht über Al 93/15 und Al 93/18, Institut für Mechanische Verfahrenstechnik, Universität Stuttgart 1981

|11|. Kannenberg, H.-H.: Messung des Abischeidegrades einer Vollmantel-Schneckenzentrifuge, Diplomarbeit, Fakultät für Maschinenwesen und Elektrotechnik, Technische Hochschule Braunschweig 1962

$|12|$ Anton, H.: Messung des Abscheidegrades einer Vollmantel schneckenzentrifuge, Diplomarbeit, Fakultät für Maschinenwesen und Elektrotechnik, Technische Hochschule Braunschweig 1962

$|13|$. Hesse, H.: Untersuchung des Abscheidegrades eines Dekanters giplomarbeit, Fakultät für Maschinenwesen und Elektrotechnik, Technische Hochschule Braunschweig 1962 
$|14|$ Burger, M.: Aufbau des Versuchsstandes für eine Dekantierzentrifuge und Aufnahme typischer Kennlinien, Diplomarbeit, Fakultät fur Chemieingenieurwesen, Universität Karlsruhe 1980

|15| Iangeloh, T.: Untersuchung der Klärung in Dekantierzentrifugen, Diplomarbeit. Fakultät für Chemieingenieurwesen. Universität Karlsruhe 1981

| $16 \mid$ P 3139 345.4, Dekanter-Vorrichtung, Stahl, W.

$117 \mid$ P 3142805.3 , Dekantierzentrifuge, stahl, W. 


\section{Nomenklatux}

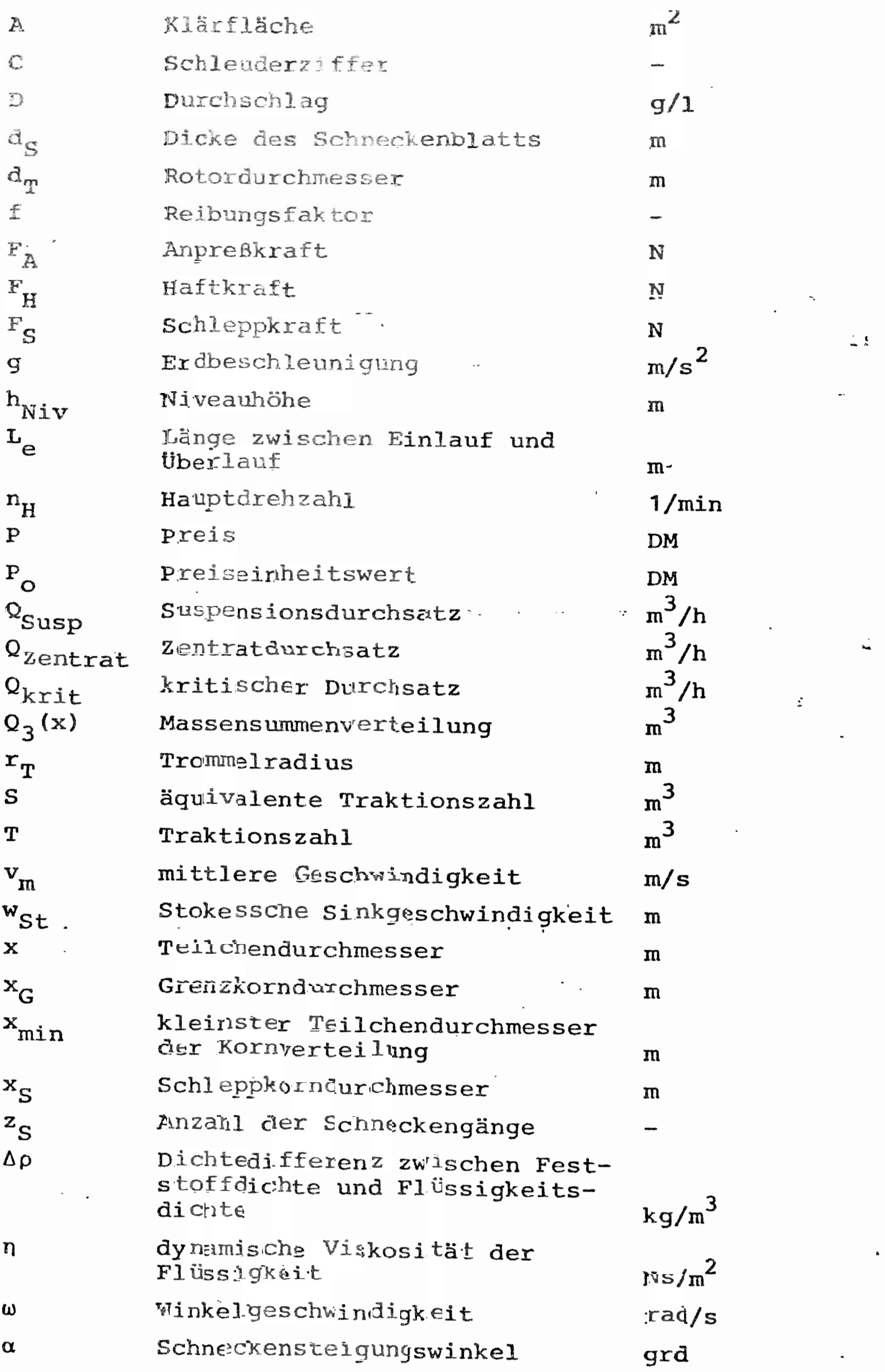

